NBER WORKING PAPER SERIES

\title{
INDEX INVESTING AND ASSET PRICING UNDER INFORMATION ASYMMETRY AND AMBIGUITY AVERSION
}

\author{
David Hirshleifer \\ Chong Huang \\ Siew Hong Teoh \\ Working Paper 24143 \\ http://www.nber.org/papers/w24143 \\ NATIONAL BUREAU OF ECONOMIC RESEARCH \\ 1050 Massachusetts Avenue \\ Cambridge, MA 02138 \\ December 2017, Revised January 2023
}

We thank Hengjie Ai, David Dicks, Stefanos Delikouras, David Easley, Bing Han, Zhiguo He, Jiasun Li, Ye Li, Olivia Mitchell, Stijn Van Nieuwerburgh, Uday Rajan, Yushui Shi, Chen Wang, Yajun Wang, Liyan Yang, and seminar and conference participants at UC Irvine, National University of Singapore, Hong Kong Polytechnic University, the Annual Conference on Financial Economics and Accounting, the American Finance Association Annual Meeting, the Annual Conference of the Financial Intermediation Research Society, Western Finance Association Annual Meeting, Stanford Institute of Theoretical Economics Summer Workshop, SFS Cavalcade, and the Mitsui Finance Symposium for very helpful comments. The views expressed herein are those of the authors and do not necessarily reflect the views of the National Bureau of Economic Research.

NBER working papers are circulated for discussion and comment purposes. They have not been peer-reviewed or been subject to the review by the NBER Board of Directors that accompanies official NBER publications.

(C) 2017 by David Hirshleifer, Chong Huang, and Siew Hong Teoh. All rights reserved. Short sections of text, not to exceed two paragraphs, may be quoted without explicit permission provided that full credit, including $(\odot)$ notice, is given to the source. 
Index Investing and Asset Pricing under Information Asymmetry and Ambiguity Aversion David Hirshleifer, Chong Huang, and Siew Hong Teoh

NBER Working Paper No. 24143

December 2017, Revised January 2023

JEL No. F3,G11,G12,G14,G15,G4,G41

\section{ABSTRACT}

In a setting with information asymmetry and a tradable value-weighted market index, ambiguity averse investors hold undiversified portfolios, and assets have nonzero alphas. But when a passive fund offers the risk-adjusted market portfolio ( $R A M P)$, whose weights depend on information precisions as well as market values, all investors hold the same portfolios as in the economy without model uncertainty and thus engage in index investing. So RAMP improves participation and risk sharing. Asset alphas are zero with $R A M P$ as pricing portfolio. $R A M P$ can be implemented by a fund of funds even if no manager individually has sufficient knowledge to do so.

David Hirshleifer

Marshall School of Business

University of Southern California

3670 Trousdale Pkwy

Los Angeles, CA 90089

and NBER

hirshlei@marshall.usc.edu

Chong Huang

SB2 438, Paul Merage School of Business

UC Irvine

CA 92697-3125

Irvine, CA 92617

chong.h@uci.edu
Siew Hong Teoh

The Paul Merage School of Business

University of Irvine

Irvine, CA 92697-3125

steoh@uci.edu 


\section{Introduction}

Index investing has long been recommended by distinguished practitioners, such as Jack Bogle and Warren Buffett, and leading scholars, such as William Sharpe and Harry Markowitz, as an attractive means for retail investors to optimize risk and return. In recent years, investors have increasingly followed this recommendation. ${ }^{1}$ Market indexes are also important in asset pricing: they are used as pricing portfolios for determining assets' risk premia.

The design of the index is central to how well it serves these roles of facilitating stock market investment and of pricing assets in the cross section. In the Capital Asset Pricing Model (Sharpe 1964; Lintner 1965), the Value-Weighted Market Portfolio (VWMP) serves both these roles. In equilibrium, all investors hold the VWMP, and with the $V W M P$ as the pricing portfolio, correctly priced assets have zero alphas.

In practice, however, investors have heterogeneous beliefs and are imperfectly rational, violating the CAPM assumptions. Investors observe different signal values, and their signals can differ in precision. So even if informed investors were rational, if there is some noise in the system, investors would not hold the same portfolio. Indeed, Admati (1985) shows that in such a setting, the VWMP is not mean-variance efficient for any information set.

Furthermore, laboratory and field evidence indicates that investors usually face model uncertainties (i.e., they do not know exactly financial market parameters). This can cause investors to perceive the stock market as very risky, potentially discouraging market participation and increasing risk premia. ${ }^{2}$ In the absence of model uncertainty, investors glean information from asset prices, which partially aggregates other investors' information. ${ }^{3}$ This reduces the conditional variance of asset prices, and encourages market participation.

However, if investors face model uncertainty (also known as ambiguity), they may

\footnotetext{
${ }^{1}$ For example, the Wall Street Journal article "Index Funds Are the New Kings of Wall Street" indicates that "Funds that track broad U.S. equity indexes hit \$4.27 trillion in assets as of Aug 31, 2019, according to research firm Morningstar Inc., giving them more money than stock-picking rivals for the first-ever monthly reporting period. Funds that try to beat the market had $\$ 4.25$ trillion as of that date."

${ }^{2}$ Dimmock, Kouwenberg, and Wakker (2016), Dimmock et al. (2016), and Bianchi and Tallon (2018) measure ambiguity attitudes using artificial events based on Ellsberg urn experiments. Anantanasuwong et al. (2019) directly elicit ambiguity attitudes using an incentivized survey. These studies provide evidence suggesting that ambiguity aversion reduces market participation.

${ }^{3}$ Investor learning from asset prices has been extensively studied in rational expectations equilibrium models, such as Grossman and Stiglitz (1980), Hellwig (1980), and Admati (1985).
} 
find it much harder to extract information from asset prices, since prices depend upon unknown financial market parameters, not just private information. Investors' aversion to uncertainty may cause them to take zero positions in assets they are ambiguous about. As we show, such non-participation may obstruct the aggregation of information in asset prices, and undermine the roles of the VWMP as a common holding of investors and as a pricing portfolio.

These points suggest that in a financial market with information asymmetry and ambiguity averse investors, the VWMP does not facilitate investor stock market participation, and that assets are not priced according to their loadings on this index. ${ }^{4}$ This raises the question of whether a different index can be designed that investors will use and benefit from? If so, how is it constructed? Do investors with heterogeneous information signals and ambiguity aversion all invest in this index? Can assets be priced relative to such an alternative index?

We address these questions in a noisy rational expectations equilibrium setting with ambiguity averse investors who do not know some parameters of the financial market and optimize under worst-case assumptions (Gilboa and Schmeidler 1989). We introduce a new index portfolio, whose weights are functions of the financial market parameters. We then introduce the possibility that there is a passive index fund that knows the true financial market parameters and commits to offering this index portfolio. ${ }^{5}$

The key to the index design is to have asset weights depend appropriately upon the precisions of investor private signals and the precisions of random supply shocks, as well as the market values of assets. Specifically, the index is constructed as the optimal portfolio that an investor who does not have private signals about asset payoffs would choose in a setting without model uncertainty. Relative to the VWMP, such a new index has lower investment in more volatile assets (conditional on asset prices). In other words, it is a defensive (low volatility) investing strategy. Therefore, holding this new index is less risky than holding the VWMP. We call this index the Risk-Adjusted Market

\footnotetext{
${ }^{4}$ We formally show the dysfunctions of the VWMP in Appendix B. In equilibrium, ambiguity averse investors do not hold the VWMP, since they perceive that the VWMP is extremely risky in the worst-case scenario. So the VWMP fails to help ambiguity averse investors with index investing. In addition, since the VWMP is not mean-variance efficient for public information, and ambiguity averse investors do not participate in the markets of assets they are ambiguous about, assets have non-zero alphas relative to the VWMP.

${ }^{5}$ In the baseline model, we abstract away agency problems and fund fees to focus on the question of whether a well-designed index portfolio can mitigate the adverse effects of ambiguity aversion. In Section 4 , we consider how such an index investing strategy can be implemented, and which agents may be best positioned to offer such a fund.
} 
Portfolio (RAMP).

Investors have common knowledge of how RAMP is constructed as a function of financial market parameters. However, investors who are ambiguous about the financial market do not know the exact composition of RAMP (since they do not know some financial market parameters). RAMP does not rely on private information about asset payoffs, so RAMP is still (in this sense) a passive index. In particular, RAMP can be viewed as a "smart beta" investing strategy, a general approach that recently has gained popularity in investment practice. ${ }^{6}$

However, it is not obvious whether a passive fund offering RAMP can attract ambiguity averse investors. RAMP may potentially be perceived to be extremely risky given some investors' subjective beliefs about the financial market. Also, different investors have different subjective beliefs about the structure of the financial market and different private signals about asset payoffs. So it is unclear whether one passive fund can be a useful component of the optimal portfolios of all investors.

The main result of this paper is that there is an equilibrium in which investors' asset holdings are exactly the same as those in the economy without model uncertainty. All investors, whether facing model uncertainty or not, hold exactly one share of RAMP by delegating the passive component of their portfolios to the index fund. Investors additionally hold investor-specific positions based upon their private information signals. So partial delegation by investors of portfolio choice to the index fund solves the problem of ambiguity aversion and nonparticipation.

A surprising property of the equilibrium that we identify is that investors hold the same number of shares of the fund, provided that they have the same risk tolerance. In equilibrium, investors with the same risk tolerance may disagree heavily for two reasons. First, investors who have different private signals about asset payoffs hold different beliefs. Furthermore, a pair of investors who have non-overlapping subjective belief supports about financial market parameters disagree about the composition of $R A M P$. So investors form different estimates of return and risk of RAMP. Nevertheless, these heterogeneity do not lead to different index investments. Furthermore, we show that $R A M P$ is the correct portfolio for pricing all the assets in the capital market. In equilibrium, assets' alphas relative to RAMP are zero, implying a new version of CAPM security market line under information asymmetry and ambiguity aversion.

\footnotetext{
${ }^{6}$ Smart beta strategies seek to passively follow indexes that use alternative weighting schemes, such as making weights a function of volatility, rather than weighting solely by traditional market capitalization.
} 
The key intuition for why investors hold RAMP as the passive component of their portfolios derives from a new separation theorem that applies in the setting with no model uncertainty. Without model uncertainty, there is a rational expectations equilibrium in which any investor's equilibrium risky asset holding can be decomposed into two components. The first is just RAMP, which is a common deterministic component of all investors' equilibrium holdings. The second is the investor's information-based portfolio, which includes a non-zero position in an asset if and only if the investor receives a private signal about the asset.

Our new separation theorem differs from the separation theorem derived in the literature in that an investor's optimal portfolio is separated by her conditionally independent signals of asset payoffs. ${ }^{7}$ We therefore call it the Information Separation Theorem. Specifically, RAMP is an investor's equilibrium holding, when she trades based only on public information. In contrast, an investor's information-based portfolio is her optimal portfolio based on her private signals and conditional on asset prices (as exogenous parameters). So any investor's information-based portfolio is independent of public information.

The Information Separation Theorem provides new insight into why the investors' equilibrium asset holdings in the setting where investors are subject to model uncertainty are the same as in the economy without model uncertainty. Consider the strategy profile in which each investor holds exactly one share of the fund, and additionally holds her information-based portfolio (which could be a nullity). Given that all other investors behave as prescribed, no investor has an incentive to deviate.

The key insight is that the fund provides investors with a channel to share risks. Consider, for example, an investor and a vector of parameters of a financial market that is possible according to her subjective belief. Given the value of this vector, the investor would be in a possible world without model uncertainty. Since all other investors are holding one share of the fund and their own information-based portfolios, they are effectively holding the same portfolios as they would in the rational expectations equilibrium in this world, even if they perceive different values of the vector. Hence, the market clearing condition implies that the pricing function is the same as the one in the

\footnotetext{
${ }^{7}$ This separation holds generally under mean-variance preferences. It derives from the model assumption that investors are price takers, so that an investor's private signal and the price signal are conditionally independent. By Bayes' rule, it follows that investors can optimally construct a portfolio based on each of her signals and then sum all the constructed portfolios together to get the equilibrium asset holdings.
} 
rational expectations equilibrium. Therefore, if the investor knew the parameter values that characterize this possible world, her optimal portfolio choice would consist of $R A M P$ and her own information-based portfolio.

Because the fund offers RAMP in any possible world, without the knowledge of the exact world, the investor's optimal portfolio choice is to hold one share of the fund together with her own information-based portfolio. Investors may disagree with each other about financial market parameters (owing to having different prior supports of their distributions) and thus the fund's composition and risks. Nevertheless, by holding one share of the fund along with their own information-based portfolios, each investor knows that her position is, in the proposed equilibrium, optimal under each possible value of the financial market parameter vector. When other investors trade as prescribed, the optimal non-informational component of the investment strategy, assuming that the investor knows the financial market parameters, is independent of the particular values of these parameters. This implies that this portfolio component maximizes the investor's utility in the worst-case scenario, or more technically, solves the investor's max-min utility. Put differently, a strong max-min property holds in the equilibrium. Therefore, ambiguity averse investors all hold the same diversified portfolio, RAMP, by holding the passive fund.

The above argument makes clear that an investor's willingness to hold the fund relies crucially on equilibrium reasoning. Each investor understands that all other investors hold the fund and their own information-based portfolios. Indeed, if an ambiguity averse investor thought that other investors were not choosing RAMP as their non-informational positions, she would not in general find it optimal to hold the fund.

In other words, the fact that investors hold RAMP is not just a consequence of benefits to diversification - benefits which are present even in a partial equilibrium setting. The willingness to hold RAMP depends on more than this - an understanding that other investors will, in equilibrium, also hold RAMP. Hence, it is only in equilibrium, and by virtue of the Information Separation Theorem, that we can conclude that ambiguity averse investors optimally hold the fund offering RAMP.

Notably, RAMP does not solve the problem of model uncertainty by eliminating it; it solves the problem by providing an attractive vehicle for risk sharing. ${ }^{8}$ Although

\footnotetext{
${ }^{8}$ Mele and Sangiorgi (2015) show that in a model without a passive fund offering RAMP, ambiguity averse investors acquire costly information about model parameters, which helps reduce model uncertainty. In comparison with their finding, our results indicate that delegation can serve as a substitute for information acquisition as a means of addressing ambiguity aversion.
} 
investors agree to hold the fund in equilibrium, they disagree on its composition, since investors have heterogeneous uncertainties about the financial market parameters that $R A M P$ is a function of. So even when RAMP is offered to investors, model uncertainty in equilibrium remains.

Furthermore, compared with a passive fund offering the VWMP, a RAMP fund encourages more investors to participate in the financial market, increasing the demand for risky assets. Hence, for a given pair of asset payoffs and random supply shocks, the financial market with a RAMP fund has higher asset prices and the same price volatility. Therefore, the equilibrium asset risk premia in the financial market with a RAMP fund are lower.

Another consequence of the Information Separation Theorem is that all assets have zero alphas relative to RAMP. The fact that an investor with no private information optimally holds RAMP (through the fund) implies that RAMP is mean-variance efficient for all possible values of the ambiguous parameters. So the CAPM security market line holds with RAMP as the pricing portfolio regardless of the actual values of the financial market parameters. Because the pricing portfolio does not depend on the realization of the random supply shock, and the weight of each asset in the pricing portfolio are conditional on asset prices, which are publicly observable, the portfolio is potentially observed by an econometrician. This makes the model empirically testable.

Given the potential benefits of RAMP to investors, it is important to consider whether the portfolio is implementable in practice as an index fund. Since RAMP is constructed based on knowledge about capital market but not on information about specific assets' returns, it is a passive index, which can be constructed and maintained by a professional index committee or an index company. Once such an index is available, index funds and ETFs can track it, and their incentives to maintain their reputations can make credible their commitments to offering RAMP.

One premise for such an implementation approach to work is the existence of an agent, such as an index committee or an index company, that knows all parameters of the financial market, enabling it to offer a RAMP index. We show that this is not a necessary condition for $R A M P$ to be made available to investors. Suppose instead that no single agent knows all parameters of the financial market. Nevertheless, as long as each parameter is known by some agents, knowledgeable agents can start competitive sector funds (e.g., geography-specific funds or industry-specific funds). This enables investors at large to hold RAMP by holding all the sector funds. To put this another way, 
it is possible to offer RAMP by creating a fund of funds. This can enable the formation of $R A M P$ funds and improve market participation and risk sharing.

Our findings contribute to the growing literature on the economic consequences of index investment. Chabakauri and Rytchkov (2016) find that the introduction of index trading increases volatilities and correlation of stock returns and that such an effect arises from the improved risk sharing. Bond and García (2018) show that as indexing becomes cheaper, indexing increases while individual asset trading decreases, and aggregate price efficiency decreases while relative price efficiency increases. Baruch and Zhang (2018) prove that it is optimal for nonindex investors to index and establish a version of CAMP in a very different economic setting.

All these papers assume that some investors are constrained to make index investing. In contrast, our paper assumes that all investors can freely employ index investing strategy and analyzes how a newly designed market index affects portfolio choice and asset pricing in financial markets with information asymmetry and ambiguity averse investors.

Past literature has analyzed extensively the extent to which ambiguity aversion hinders market participation and leads to inefficiency. Early work mainly considers investor uncertainty about the first moment of asset payoffs and study market participation decisions in partial equilibrium frameworks. ${ }^{9}$ Recent papers, such as Condie and Ganguli (2011), Condie and Ganguli (2017), and Illeditsch, Condie, and Ganguli (2019), study the effects of investor ambiguity about the characteristics of private or public information in rational expectations equilibrium settings, and show that asset prices may be informationally inefficient. Our paper differs from this literature in considering investor model uncertainty about general parameters that determine asset payoff distributions in a rational expectations equilibrium setting, and in studying index investing as a way to address ambiguity aversion.

A very different version of the CAPM has been derived in somewhat similar model setups where all investors are perfectly rational (see, for example, Easley and O'Hara (2004), Biais, Bossaerts, and Spatt (2010), and the online appendix of Van Nieuwerburgh

\footnotetext{
${ }^{9}$ See, e.g., Bossaerts et al. (2010), Cao, Wang, and Zhang (2005), Dow and Werlang (1992), Easley and O'Hara (2009), Easley and O'Hara (2010), Epstein and Schneider (2010), and Cao, Han, Hirshleifer, and Zhang (2011)). An exception is Epstein and Schneider (2008) who assume that investors are uncertain about their signals' qualities and so dislike assets for which information quality is poor. These induce ambiguity premia. Another exception is Watanabe (2016), who assumes that investors are ambiguous about the mean of the asset's random supply shock. The focus of Watanabe's paper is on market fragility.
} 
and Veldkamp (2010)). These papers do not separate investor equilibrium asset holdings and do not obtain zero-alphas conditional on public information (using the VWMP as the pricing portfolio) for correctly priced assets. Instead, in these models, the market portfolio for CAPM pricing is the ex-post total supply of the risky assets, the sum of the endowed risky assets and the random supply of risky assets. This market portfolio is mean-variance efficient conditional on the average investor's information set, and so the CAPM security market line holds from the perspective of the average investor.

The version of the CAPM security market line we derive differs in that the pricing portfolio is $R A M P$, which is determined ex ante (prior to the realization of the random supply shocks), and in that risk premia are conditional only upon the public information (market prices). This makes the market portfolio more directly observable to an econometrician. Furthermore, since RAMP is mean-variance efficient for any possible parameters of the financial market, the CAPM security market line holds even when investors are ambiguity averse.

Our setting endogenizes investor trust in fund managers (Gennaioli, Shleifer, and Vishny 2015). An insight provided by our approach is that inducing investors to make index investing requires more than investor trust in the honesty and superior knowledge of fund managers about the financial market. It is crucial that investors foresee an equilibrium in which other investors also trust the fund managers and trade accordingly. Off equilibrium, an investor would not be willing to hold the fund, even if she trusted the fund manager.

In a working paper, Li and Wang (2018), a representative investor faces model uncertainty about the financial market and so is uncertain about the composition of the efficient portfolio offered by a fund based on the fund's knowledge of the financial market. They call such an uncertainty the "delegation uncertainty." In their partial equilibrium setting where there is no risk sharing, the delegation uncertainty causes the investor to partially delegate, leading to higher CAPM alphas. By contrast, in our model with $R A M P$, delegation uncertainty is endogenously eliminated by risk sharing among investors: holding one share of the fund and the information-based portfolio is optimal to an investor in every possible world in her subjective belief support, when other investors are employing the same investment strategy. So an investor is not concerned about the exact asset holdings through the fund, which vary across possible worlds in her belief support. 


\section{The Financial Market}

A continuum of investors with measure one, who are indexed by $i$ and uniformly distributed over $[0,1]$ trade assets at date 0 and consume at date 1 .

Assets. At date 0 , each investor $i$ can invest in a riskfree asset and $N \geq 2$ risky assets. ${ }^{10}$ At date 1 , the riskfree asset pays $r$ units, and risky asset $n$ pays $f_{n}$ units of the single consumption good. In addition to trading directly, investors can also hold individual risky assets through a passive fund that commits to offering a portfolio $X$, which is an $N$-dimension column vector with the $n^{\text {th }}$ element being the shares of the $n^{\text {th }}$ risky asset in $X$.

Letting $D_{i}$ be the vector of shares of the risky assets held by investor $i$, and $d_{i}$ (a scalar) the shares of the fund held by investor $i$, investor $i$ 's effective risky asset holding is $d_{i} X+D_{i}$.

Return Information. Let $F=\left(f_{1}, f_{2}, \ldots, f_{N}\right)^{\prime}$ be the vector of risky assets' returns. We assume that all investors share a common uniform improper prior of $F$, and so no investor has prior information about any risky asset's return. ${ }^{11}$ Each investor $i$ receives a vector of private signals $S_{i}$ about asset returns, $S_{i}=F+\epsilon_{i}$, where $F$ and $\epsilon_{i}$ are independent; and $\epsilon_{i}$ and $\epsilon_{j}$ are also independent. Each $\epsilon_{i}$ is normally distributed, with mean zero and precision matrix $\Omega_{i}$. Since $\Omega_{i}$ is the inverse of the variance-covariance matrix of $\epsilon_{i}$, it is symmetric and positive definite. Note that we do not require $\Omega_{i}$ to be diagonal; hence, investor $i$ 's private signal about asset $n$ 's payoff may be correlated to that of asset $k$.

Letting $\Sigma$ be the matrix of the average precision of private signals, we have

$$
\Sigma=\int_{0}^{1} \Omega_{i} \mathrm{~d} i
$$

In addition, as is standard, the independence of the errors implies that in the economy as a whole investor private signal errors average to zero, so that the equilibrium pricing function does not depend on the error realizations (though it does depend on their

\footnotetext{
${ }^{10}$ To simplify notation, we assume that the number of risky assets $N$ is common knowledge. However, our results hold in an extension where investors are also ambiguous about the total number of risky assets.

${ }^{11}$ The uniform improper prior assumption is for simplicity. In Section 5.1, we study the case in which investors have (potentially uncertain) normal priors of $F$. We show that with a modified portfolio offered by the passive fund, our results still hold.
} 
distributions). Therefore, we have

$$
\int_{0}^{1} \Omega_{i} S_{i} \mathrm{~d} i=\Sigma F
$$

Random Supply. Let $Z$ denote the random vector of supplies of all risky assets. We assume that $Z$ is independent of $F$ and of $\epsilon_{i}$ (for all $i \in[0,1]$ ). We further assume that $Z$ is normally distributed with mean 0 and the precision matrix $\boldsymbol{U}$. Here, $\boldsymbol{U}$ is also symmetric and positive definite.

Model Uncertainty and Ambiguity Aversion. Taking the riskfree asset to be the numeraire, let $P$ be the price vector of the risky assets. Also, let $W_{i}=\left(w_{i 1}, w_{i 2}, \ldots, w_{i N}\right)^{\prime}$ be the endowed shareholdings of investor $i$. We assume that the aggregate endowments of shares of each stock are strictly positive; that is, $W=\int_{0}^{1} W_{i} \mathrm{~d} i \gg 0$. Then investor $i^{\prime} \mathrm{s}$ final wealth at date 1 is

$$
\Pi_{i}=r\left[W_{i}^{\prime}-\left(d_{i} X^{\prime}+D_{i}^{\prime}\right)\right] P+\left(d_{i} X^{\prime}+D_{i}^{\prime}\right) F .
$$

The first term is the return of investor $i$ 's investment in the riskfree asset, and the second term is the total return from her investments in risky assets.

Since investor $i$ is risk averse, if she knows all model parameters, at date 0 she maximizes a CARA expected utility function,

$$
\mathbb{E}_{i} u\left(\Pi_{i}\right)=\mathbb{E}_{i}\left[-\exp \left(-\frac{\Pi_{i}}{\rho}\right)\right] .
$$

The expectation in equation (4) is taken based on investor $i$ 's information about asset returns. Since the common prior about asset returns is uninformative, any investor $i$ 's information consists of the equilibrium price vector and the realization of a private signal $S_{i}$ only.

However, investor $i$ may be subject to model uncertainty. We assume that all parameters are common knowledge among investors, except the average private signal precision $\Sigma$, the random supply shock precision $U$, and the aggregate endowments of shares $W$. Therefore, we characterize a financial market, or a model, by $m=(\boldsymbol{\Sigma}, \boldsymbol{U}, W)$, and the set of all possible financial markets is denoted by $\mathcal{M}$. Let the nonempty set $\mathcal{M}_{i} \subseteq \mathcal{M}$ be the support of investor $i$ 's subjective belief over possible models. Then, when $\mathcal{M}_{i}$ is not a singleton, we say that investor $i$ is subject to model uncertainty. ${ }^{12}$

\footnotetext{
${ }^{12}$ We do not specify an ambiguity averse investor $i^{\prime}$ s subjective belief over $\mathcal{M}_{i}$ and their subjective beliefs about other investors' subjective beliefs, since these will not affect our equilibrium characterization, as will become clear shortly.
} 
We further assume that when investor $i$ is subject to model uncertainty, she is ambiguity averse. Hence, she chooses an investment strategy $\left(d_{i}, D_{i}\right)$ to maximize the infimum of her CARA utility. Formally, each investor $i$ 's decision problem is ${ }^{13}$

$$
\max _{d_{i}, D_{i}} \inf _{m_{i} \in \mathcal{M}_{i}} \mathbb{E}_{i}\left[-\exp \left(-\frac{\Pi_{i}}{\rho}\right)\right] .
$$

We assume that the passive fund knows the true model but does not have any private information about asset payoffs. Hence, the fund commits to offering the portfolio $X$ based only on its knowledge of the model and the asset prices. ${ }^{14}$

Equilibrium. In our model, an investor $i$ 's investment strategy is a mapping from her subjective belief support $\mathcal{M}_{i}$, her private signals $S_{i}$, and asset prices $P$ to the shares of assets she wants to hold directly, $D_{i}$, and the shares of the fund she wants to hold, $d_{i}$. We are interested in an equilibrium defined as follows.

Definition 1. A pricing vector $P^{*}$ and a profile of all investors' risky asset holdings $\left\{d_{i}^{*}, D_{i}^{*}\right\}_{i \in[0,1]}$ constitute an equilibrium, if:

1. Given $P^{*},\left(d_{i}^{*}, D_{i}^{*}\right)$ solves investor $i^{\prime}$ s maximization problem in equation (5), for all $i \in$ $[0,1]$; and

2. $P^{*}$ clears the market,

$$
\int_{0}^{1}\left(d_{i}^{*} X+D_{i}^{*}\right) \mathrm{d} i=W+Z, \quad \text { for any realizations of } F \text { and } Z .
$$

\section{The Risk-Adjusted Market Portfolio}

The conventional stock market index is the value-weighted market portfolio (VWMP), which, in our model, is $X=W$. However, as we show in Appendix B, the VWMP fails to encourage better diversification and risk sharing by ambiguity averse investors, and fails as a benchmark for equilibrium asset pricing. The dysfunctions of the VWMP

\footnotetext{
${ }^{13}$ An investor's utility in this paper differs slightly from that defined in Gilboa and Schmeidler (1989). Since $\mathcal{M}_{i}$ may be a non-compact set, the investor maximizes the infimum rather than the minimum of her CARA utility among all possible models in $\mathcal{M}_{i}$.

${ }^{14}$ The fund behaves non-strategically in our model. Allowing for agency problem would add analytical complexity. However, it is an immediate implication of Proposition 1 that if the passive fund wants to maximize the measure of investors who buy its shares, the optimal portfolio it commits to offering is the one specified in equation (7).
} 
derive from important limitations: assets are weighted in the VWMP by their market capitalizations only, so these weights depend upon neither the average precision of private signals nor the precision of random supply, which determine the distribution of price signal.

This raises the question of whether there is an alternative index which, if offered by a fund, ambiguous investors would be willing to hold. If so, this could improve diversification and risk-sharing between investors who are ambiguous about any given asset and those who are not. We will show that a new index design achieves these goals.

The index is formed by adjusting the market capitalization weights in the VWMP by the average precision of investor private signals and the precision of random supply. We dub the new index the Risk-Adjusted Market Portfolio (RAMP), because as we will show, it places lower weight on more volatile stocks than the VWMP does. We analyze portfolio choices and asset pricing, when there is a passive fund offering RAMP.

Formally, RAMP is defined as

$$
X=\left[\boldsymbol{I}+\frac{1}{\rho^{2}}(\boldsymbol{\Sigma} \boldsymbol{U})^{-1}\right]^{-1} W .
$$

Investors who are subject to model uncertainty do not know $\Sigma, U$, or $W$, and hence do not know the exact composition of $X$. However, the functional relationship between $X$ and $(\boldsymbol{\Sigma}, \boldsymbol{U}, W)$ that is specified in equation (7) is common knowledge to investors. RAMP does not depend on any of the private signals about asset payoffs, and so RAMP is a passive asset management product. Because of these features (i.e., passive but weighting assets not only by market capitalization), RAMP can be viewed as a type of smart beta strategy, an investing approach which has been growing in popularity in investment practice. $^{15}$

More specifically, RAMP is a defensive investment strategy in the sense that it underweights high volatility stocks. RAMP differs from VWMP in that it contains a component $(\Sigma \boldsymbol{U})^{-1}$. It then follows from equation (7) that RAMP includes fewer shares of more volatile assets. Therefore, holding RAMP will be a defensive investment strategy that can largely reduce the risk of loss.

\footnotetext{
${ }^{15}$ By the end of December 2017, smart beta funds have surpassed $\$ 1$ trillion in assets under management.
} 


\subsection{Equilibrium Index Investing}

Even though RAMP is offered based on the true parameters of the financial market, it is not obvious that an ambiguity averse investor will be willing to hold the fund. The investor does not know its exact composition, so holding it entails bearing extra risk. Furthermore, different investors may have different subjective beliefs about the structure of the financial market, which might make it seem unlikely that one market index can attract all investors. For example, when investor $i$ and investor $j$ completely disagree with each other about the financial market, i.e., $\mathcal{M}_{i} \cap \mathcal{M}_{j}=\varnothing$, it seems plausible that the optimal market index for investor $i$ would differ from that for investor $j$.

However, we show in this subsection that with the passive fund offering RAMP, all investors employ the index investment strategy in equilibrium by holding one share of the fund, and their effective asset holdings are exactly the same as in the economy without model uncertainty. This is stated in Proposition 1.

Proposition 1. In the model with a passive fund that commits to offering the portfolio X specified in equation (7), there is an equilibrium in which

1. All investors will buy one share of the passive fund, and so $d_{i}^{*}=1$ for all $i \in[0,1]$;

2. Any investor $i$ will hold an extra portfolio $D_{i}^{*}=\rho \boldsymbol{\Omega}_{i}\left(S_{i}-r P\right)$; and

3. For any given $F$ and $Z$, the equilibrium price is

$$
P=B^{-1}[F-A-C Z],
$$

where

$$
\begin{aligned}
& A=\frac{1}{\rho}\left[\rho^{2}(\boldsymbol{\Sigma} \boldsymbol{U} \boldsymbol{\Sigma})+\boldsymbol{\Sigma}\right]^{-1} W \\
& \boldsymbol{B}=r \boldsymbol{I} \\
& \boldsymbol{C}=\frac{1}{\rho} \boldsymbol{\Sigma}^{-1} .
\end{aligned}
$$

The intuition of Proposition 1 builds upon the Information Separation Theorem, which applies in the setting without model uncertainty (that is, $m$ is common knowledge among investors). Making use of a standard formula for investor equilibrium asset holdings in traditional rational expectations equilibrium models (see Admati (1985)), we prove the following Information Separation Theorem in Appendix C. 
Theorem 1 (The Information Separation Theorem). When the characteristics of all assets are common knowledge, equilibrium portfolios have three components: a risk-adjusted market portfolio (RAMP); an information-based portfolio based upon private information and equilibrium prices but no extraction of information from prices; and the riskfree asset.

The Information Separation Theorem states that in a setting without model uncertainty, any investor $i$ 's equilibrium risky asset holding can be decomposed into two components. The first component is the optimal portfolio based on the price information gleaned from the stock price only, and hence is common among all investors. Such a component is just RAMP (the portfolio $X$ evaluated at the commonly known $m$ ). The second component is $\rho \boldsymbol{\Omega}_{i}\left(S_{i}-r P\right)$, the optimal portfolio based on investor $i$ 's private signal only, and hence is called the information-based portfolio. Importantly, the price signal and investor $i$ 's private signal are conditionally independent, and so these two components can be formed independently.

With the Information Separation Theorem, we are now in a position to derive the intuition for investors' equilibrium investment strategies in the setting with model uncertainty. We consider a strategy profile in which all investors hold one share of the passive fund and their own information-based portfolio. We will then argue that no investor has an incentive to deviate unilaterally from such a strategy.

To build intuition, we first consider investors with min-max preferences, and then show that our conclusions also apply to max-min preferences as well. With min-max preferences, we argue that given other investors' strategies of holding RAMP and their own information-based portfolios, an investor's optimal trading strategy is constant across all possible values of financial market parameters in her subjective belief support. Hence, the investor's optimal trading strategy with max-min utility is the same as that with min-max utility.

Specifically, when investor $i$ has a min-max utility, for each possible world $m_{i} \in \mathcal{M}_{i}$, she can solve her optimal risky asset holdings, assuming that the equilibrium pricing function is the one in equation (8) with $m$ being $m_{i}$. Importantly, because all other investors are holding one share of the fund along with their own direct information-based portfolios, they are effectively holding the risky assets as in the world with $m_{i}$ being common knowledge. Therefore, in the possible world $m_{i}$, the market clearing condition implies that the pricing function is the one specified in equation (8) with $m$ being $m_{i}$. That is, investor $i$ 's belief about the pricing function is correct. So, she would like to hold the risky assets as in the world $m_{i}$. Such risky asset holdings can be implemented by 
holding one share of the passive fund and her information-based portfolio, so investor $i$ would like to use the investment strategy in Proposition 1. Furthermore, investor $i$ is still uncertain about $m$, so holding the risk-adjusted market portfolio through holding one share of the fund is strictly preferred.

In the above, for any given possible world, holding one share of the fund and her own information-based portfolio maximizes investor $i$ 's expected CARA utility (given that all other investors trade according to the prescribed strategy profile). Since such a trading strategy is optimal across all possible values of financial market parameters, it maximizes investor $i$ 's max-min utility. That is, a strong max-min property holds in the equilibrium, and hence, in our model with investors having max-min utilities, the investment strategy of holding one share of the fund and the information-based portfolio is also optimal to investors.

So the Information Separation Theorem helps explain why ambiguity averse investors are willing to hold the fund that offers RAMP in an equilibrium. Indeed, the same argument can also be applied when investors have the smooth ambiguity preferences (Klibanoff, Marinacci, and Mukerji 2005). Since holding one share of the passive fund and her own information-based portfolio helps an investor to achieve the optimal balance between risks and returns in each possible model in her subjective belief support, the optimal investment strategy will be independent of the utility representations of ambiguity preference.

\subsection{Properties of the Equilibrium}

The equilibrium characterized in Proposition 1 has several interesting properties describing behavior when a RAMP index fund is available. First, investors all hold exactly one share of the fund, even though they have heterogeneous priors about the financial market and thus different beliefs about the fund's composition. ${ }^{16}$ This is true even in the extreme case in which two investors, $i$ and $j$, completely disagree about the financial market parameters; that is, $\mathcal{M}_{i} \cap \mathcal{M}_{j}=\varnothing$. By Proposition 1, both investor $i$ and investor $j$ hold one share of the passive fund, along with their own information-based portfolios. So differences in investors' holdings arise solely from differences in their private signals about asset payoffs, not from differences in their model uncertainties.

Second, Proposition 1 shows that the willingness of investors to buy an index is based

\footnotetext{
${ }^{16}$ For simplicity in presentation, we focus on the setting where everyone optimally holds one share of the passive fund. We show that this can be generalized to heterogeneous holdings in Section 5.2.
} 
on an understanding of equilibrium risk-sharing, rather than just a partial equilibrium understanding that there can be risk-reduction benefits to the investor in isolation to diversifying her portfolio. Specifically, consider an investor who faces model uncertainty about a subset of traded assets, and views the return distributions as exogenous. Even if she can indirectly trade those assets through a passive fund, it may not be optimal for her to do so, because she cannot calculate the fund's expected return and risk. Therefore, arguments based on the incentive of individuals to diversify do not, under radical ignorance, justify holding of the fund. In contrast, in our equilibrium setting, an investor optimally holds the fund, given her belief that other investors will also do so (together with their direct portfolios). So she is willing to hold the fund too, which achieves the benefit of optimally sharing risks with other investors. ${ }^{17}$

Proposition 1 more broadly suggests that the reason why actual investors often fail to diversify goes beyond investor ambiguity aversion. In particular, for an investor to hold the fund, all other investors need to behave according to the prescribed equilibrium strategy profile. If imperfectly rational investors reason about possible portfolios based solely on partial equilibrium risk and return arguments, portfolios containing assets that investors are ambiguous about might seem extremely risky (or in the limiting case, infinitely risky). Proposition 1 shows that, owing to equilibrium considerations, even ambiguity averse investors, if otherwise rational, will hold such assets. But actual investors may not understand the equilibrium reasoning which underlies this result.

Third, and finally, comparing the equilibrium characterized in Proposition 1 with that in Proposition 6 in the Appendix B, we can see the different effects of RAMP and $V W M P$ on the asset prices and investors' equilibrium asset holdings. Whether the passive fund offers $R A M P$ or $V W M P$, conditional on the asset payoffs, the price volatility is same. This follows from the fact that $B$ and $C$ in the equilibrium pricing function with $R A M P$ are equal to $B_{V}$ and $C_{V}$ in the equilibrium pricing function with $V W M P$, respectively. For any given asset payoffs $(F)$ and asset random supplies $(Z)$, however, the asset prices are higher in the economy with RAMP being the index, because $A<A_{V}$. So in the model, introducing a passive fund that offers RAMP helps mitigate the equity premium puzzle. This also implies that an informed investor's asset holdings based on her private signals are higher in the economy with VWMP. On the other hand, while an

\footnotetext{
${ }^{17}$ The fact that equilibrium rather than just diversification considerations are crucial for the index investment result can be seen more concretely by considering the off-equilibrium possibility that other investors trade in a fashion that causes asset prices to be almost uninformative. In such a scenario, an ambiguity averse investor would not hold the passive fund, because RAMP would be perceived as extremely risky.
} 
informed investor's asset holdings based on the price signals are the same in both the economies with RAMP and with VWMP, an ambiguity averse investor's asset holdings are higher with $R A M P$.

The market clearing condition then implies that when the passive fund offers VWMP, the informed investors trade more aggressively based on their private signals to absorb the random supplies, and hence they should receive higher premia, which can be called ambiguity premia. This in turn suggests that when the passive fund offers RAMP, the assets' ambiguity premia should disappear, which we verify in Section 3.3.

\subsection{CAPM Pricing with $R A M P$}

Proposition 1 indicates that the model with ambiguity aversion and a fund that offers $R A M P$ has an equilibrium in which investors' effective risky assets holdings are exactly the same as in the rational expectations equilibrium without model uncertainty. This suggests that asset risk premia should not have any ambiguity premia. In addition, as shown in the Information Separation Theorem, RAMP is the efficient portfolio conditional only on the price signals. This suggests that a version of CAPM security market line will hold under information asymmetry and ambiguity aversion, with RAMP as the benchmark pricing portfolio.

To formally analyze asset alphas relative to RAMP as an asset pricing benchmark, we first return to the special case of no model uncertainty. From equation (36), the equilibrium pricing function in this case is

$$
P=\frac{1}{r}\left[F-A-\frac{1}{\rho} \Sigma^{-1} Z\right],
$$

where $A=\frac{1}{\rho}\left[\rho^{2}(\boldsymbol{\Sigma} \boldsymbol{U} \boldsymbol{\Sigma})+\boldsymbol{\Sigma}\right]^{-1} W$. We then have

$$
\operatorname{diag}(P)^{-1} \mathbb{E}(F)-r \mathbb{1}=\operatorname{diag}(P)^{-1} A .
$$

Here, $\mathbb{E}(F)$ is the expected payoff conditional on the equilibrium price. The LHS of equation (13) is just the vector of the risky assets' equilibrium risk premia.

Given a realized equilibrium price, $R A M P$ has the value $P^{\prime} X$. Then the vector of the weights of risky assets in RAMP is

$$
\omega=\frac{1}{P^{\prime} X} \operatorname{diag}(P) X .
$$


Hence, conditional on the price $P$, the difference between the expected return of RAMP and the riskfree rate is

$$
\begin{aligned}
\mathbb{E}\left(R_{X}\right)-r & =\omega^{\prime} \operatorname{diag}(P)^{-1} \mathbb{E}(F)-r \\
& =\frac{1}{P^{\prime} X} X^{\prime} \operatorname{diag}(P) \operatorname{diag}(P)^{-1}(A+r P)-r \\
& =\frac{1}{P^{\prime} X} X^{\prime} A,
\end{aligned}
$$

where the expectations are all conditional on the equilibrium price.

The variance of $R A M P$ is

$$
\mathbb{V}\left(R_{X}\right)=\mathbb{E}\left[\left(\omega^{\prime} \operatorname{diag}(P)^{-1} C Z\right)\left(\omega^{\prime} \operatorname{diag}(P)^{-1} C Z\right)^{\prime}\right]=\left(\frac{1}{P^{\prime} X}\right)^{2} X^{\prime} C U^{-1} C X,
$$

and the covariance between all risky assets and $R A M P$ is

$$
\operatorname{Cov}\left(R, R_{X}\right)=\frac{1}{P^{\prime} X} \operatorname{diag}(P)^{-1} C U^{-1} C X .
$$

Let $\alpha_{X}$ be the CAPM alpha with RAMP being the pricing portfolio. From equations (13)-(16), and since $X=\rho\left(C U^{-1} C\right)^{-1} A$, we have the following proposition.

Proposition 2 (Risk Premia with Supply Shocks). In the model with all parameters being common knowledge, asset risk premia satisfy the CAPM security market line where the relevant market portfolio for pricing is RAMP.

This result may seem surprising, since investors have heterogeneous asset holdings, and since the portfolios held by informed investors are not mean-variance efficient with respect to the public information set. Nevertheless, in equilibrium, there are no extra risk premia incremental to those predicted by the CAPM using RAMP.

The CAPM pricing relation using RAMP is equivalent to the assertion that RAMP is mean-variance efficient conditional only on all public information. This efficiency can be seen from the utility maximization problem of an investor who does not have any private signals about asset payoffs. Such an investor balances the expected returns and the risks of her holdings, and her information consists of the equilibrium price only, which is the only public information in our baseline model. In equilibrium, such an investor holds $R A M P$, implying that $R A M P$ is mean-variance efficient conditional only on public information.

Privately informed investors also hold RAMP as the passive component of their portfolios; this is the piece that does not depend upon their private signals (except to the 
extent that their signals are incorporated into the publicly observable market price). In addition, they have other asset holdings to take advantage of the greater safety of assets they have more information about, and for speculative reasons based upon their private information. RAMP is not mean-variance efficient with respect to their private information sets, but it is efficient with respect to the information set that contains only publicly available information.

In the special case of asymmetric information but no model uncertainty, RAMP is a natural candidate for the CAPM pricing portfolio, because it is the common component in all investors' risky asset holdings. We show that RAMP is mean-variance efficient unconditional on any investor's private information. Therefore, the CAPM security market line relation holds without conditioning on private information, with respect to RAMP.

What is perhaps more surprising is that when there is a passive fund that offers $R A M P$, even with model uncertainty, $R A M P$ is the appropriate CAPM pricing portfolio. To see how the presence of a fund offering RAMP affects asset risk premia when there is model uncertainty, consider equilibrium asset holdings as in Proposition 1. This shows that even when investors are uncertain about the precisions of asset supply shocks, they all hold one share of the passive fund, eliminating ambiguity premia. So asset risk premia satisfy the CAPM.

Corollary 1 presents this even more surprising result.

Corollary 1. In the model where investors are subject to model uncertainty, if a passive fund offers RAMP as specified in equation (7), asset risk premia satisfy the CAPM with RAMP as the pricing portfolio.

Corollary 1 implies that RAMP outperforms $V W M P$ in a single-factor model. That is, when we replace $V W M P$ with a proxy of RAMP as the common factor in the singlefactor model, the average absolute value of estimated asset alphas will decrease. We perform preliminary tests of this prediction by using a traded low-volatility ETF (the Invesco S\&P $500^{\circledR}$ Low Volatility ETF that tracks the S\&P $500^{\circledR}$ Low Volatility Index) or a constructed volatility-weighted market portfolio as our proxy for RAMP. Both proxies share the key features of RAMP of weighting assets positively by market values and negatively by volatilities. ${ }^{18}$ The empirical results are consistent with the prediction. By using either proxy for RAMP as the common factor, the average absolute value of esti-

\footnotetext{
${ }^{18}$ RAMP differs in also taking into account a latent parameter, risk aversion, which would require more elaborate estimation than our preliminary test.
} 
mated asset alphas decreases and becomes statistically insignificantly. We present the tests and the empirical results in an Online Appendix D.1.

\section{Implementation of the $R A M P$ Fund}

We have shown that our new index, RAMP, can encourage all investors, including ambiguity averse ones, to employ index investment strategy, and thus in equilibrium investor risky asset holdings are exactly same as those in the economy without model uncertainty. Therefore, in theory, any possible inefficiency due to investors' model uncertainty can be corrected by an index fund that commits to offering RAMP. However, in practice who would we expect to be well-positioned to offer a RAMP fund? In this section, we discuss this question.

In order to offer $R A M P$, an agent needs to have full knowledge about the relevant parameter values that characterize the financial market. This kind of knowledge does not include any information related to specific companies' fundamentals, which is the focus of active funds. Hence, a RAMP index could be constructed and maintained by an index committee or company, just as is the case with most popular indexes in the current stock market. ${ }^{19}$ An index committee has professional knowledge to estimate financial market parameters, making a well-maintained RAMP index feasible.

Once the RAMP index is available, to attract investors, our model implies that the methods of its construction must be publicly announced to keep the index transparent. This allows index funds and ETFs to use this index as a benchmark.

There may be agency problems associated with these fund providers, a topic that we do not focus on in this paper. However, as Berk (2005) points out, there are implicit contracts between funds and their investors. Index funds' future investment flows depend on how well the funds track the index in the current period. This provides funds with incentives to track the index closely. Huang, Li, and Weng (2020) formalize such implicit contracts as fund reputations, which are summarized by Morningstar ratings. Therefore, we regard reputation as a tool by which index funds commit to providing $R A M P$ to investors.

The aforementioned approach of implementing a RAMP fund requires an agent,

\footnotetext{
${ }^{19}$ For example, the S\&P 500 index is maintained by the U.S. Index Committee whose members are full-time professional S\&P Dow Jones Indices' staffs. The committee meets on a monthly basis to review and update the index composition. Similarly, Russell 3000 Index is constructed and maintained by FTSE Russell Group.
} 
such as an index committee or an index company, to estimate all relevant parameters of the financial market. Fast-developing information processing technologies and "big data" are likely to further improve the feasibility of a fund estimating all relevant financial market parameters for the formation of RAMP. Implementing RAMP also requires that funds be long-lived and so care about their future flows, i.e., their reputation serves as a commitment tool. We suggest above that these two requirements are largely satisfied in current financial markets.

Furthermore, we next show that in the model, RAMP funds can be offered to investors even if no single agent (i.e., fund manager) knows all parameters about the whole capital market, and even if funds do not care about reputation.

Inspired by the fund-of-funds investment strategy and the fund disclosure requirements, we consider a mechanism design approach to implementing RAMP as a fund of funds. The main idea is to have agents (fund managers) who know parameters of a subset of assets build "sector funds." This is in the spirit of the recent rise in popularity of sector or thematic ETFs. In the model, a regulator requires funds to disclose their holdings, with penalties for failing to hold assets as the funds promise. Investors then construct RAMP using all sector funds.

Specifically, without loss of generality, we follow Van Nieuwerburgh and Veldkamp (2009) to assume that all traded assets are decomposed into $Q$ independent risk factors. Then, the vector of factor payoffs is $F=\left(f_{1}, f_{2}, \ldots, f_{Q}\right)^{\prime}$. Any investor $i$ 's private signal, $S_{i}=F+\epsilon_{i}$, is then about risk factor payoffs, and the precision matrix $\boldsymbol{\Omega}_{i}$ of the noise term $\epsilon_{i}$ is diagonal. We further assume that the precision matrix $U$ of the random supply $\mathrm{Z}$ is also diagonal. We denote by $H^{j}$ the $j^{\text {th }}$ element of RAMP defined in equation (7), so $X=\left(H^{1}, H^{2}, \ldots, H^{Q}\right)^{\prime}$.

Importantly, while there may not be one investor who knows all parameters that characterize the whole financial market, for each factor $j$, there is a positive measure of investors who know all the parameters about it. To keep the analysis simple, we assume that these investors do not possess any private signals about factor $j$ payoff, nor do they know parameters of any other factors. That is, these investors specialize in factor $j$ market and are called "factor-j-uninformed investors."

We consider a mechanism $\Gamma$ that is publicly announced and enforced by a regulator. There are three dates. At date one, based on her knowledge about the financial market and her information about factor payoffs, each investor $k$ chooses to offer a passive fund or not, and if she does, she specifies the factors she will cover and charges a management 
fee $\tau_{k}$. Since investor $k$ does not acquire new information, we assume that her marginal cost of offering a passive fund is zero. We denote by $\mathcal{A}_{j}$ the set of passive funds that cover factor $j$. At date two, investors trade all individual assets and all funds offered, as well as the riskfree asset. At date three, each fund discloses its asset holding. Let $H_{k}^{j}$ be the shares of factor $j$ included in one share of fund $k$ for any $k \in \mathcal{A}_{j}$. Then, the regulator calculates the median shares of factor $j$ included in one fund share among funds that cover factor $j$. Formally, define

$$
\widehat{H}^{j}=\underset{k \in \mathcal{A}_{j}}{\operatorname{Median}}\left\{H_{k}^{j}\right\} .
$$

The regulator then imposes a fine of $\left|H_{k}^{j}-\hat{H}^{j}\right| B$ on fund $k$, where $B>0$ is sufficiently large. The total fines collected in factor $j$ will be distributed among funds whose oneshare holdings of factor $j$ are exactly $\hat{H}^{j}$, so that the regulator has a balanced budget.

It is straightforward that in the environment described above, there is no single agent (including the regulator) who knows all the parameters that characterize the whole financial market. Also, the mechanism $\Gamma$ is designed for a static setting, so there are no future flows that can incentivize funds to choose the optimal portfolios for their investors. Nevertheless, we show that the equilibrium outcome in Proposition 1 is Nashimplementable by $\Gamma$. That is, as shown in Proposition 3, the mechanism $\Gamma$ has a Nash equilibrium in which investors effectively hold assets exactly as they do in Proposition 1.20

Proposition 3. The mechanism $\Gamma$ has a Nash equilibrium in which

1. Any factor-j-uninformed investor $k$ offers a sector fund, and one share of its holding is $H_{k}^{j}=H^{j}$.

2. No investor outside the group of factor-j-uninformed investors offers a passive fund that covers factor $j$.

3. The management fee charged by any sector passive fund $k$ is $\tau_{k}=0$.

4. An investor $i$ holds one share at one and only one sector fund that covers factor $j$ (for all $j$ ).

\footnotetext{
${ }^{20}$ Following the literature on mechanism design, we focus on whether the equilibrium outcome characterized in Proposition 1 is implementable or not by the mechanism $\Gamma$. That is, whether there is an equilibrium of $\Gamma$ in which investors have exactly same holdings as in Proposition 1 . There may be multiple equilibria of $\Gamma$, but the equilibrium multiplicity is not a focus in our paper, as it is not the focus in other mechanism design problems.
} 


\section{Any investor $i$ has an extra holding $\rho \boldsymbol{\Omega}_{i}\left(S_{i}-r P\right)$.}

The first two parts of Proposition 3 follow from the designed transfers in $\Gamma$. Since all factor-j-uninformed investors know the parameters that characterize the market of factor $j$, they can hold $H^{j}$. On the other hand, in equilibrium, the median holding of factor $j$ is $\widehat{H}^{j}=H^{j}$. Hence, any unilateral deviation by a fund $k$ will lead to a positive fine. Therefore, only factor- $j$-uninformed investors offer sector funds that cover factor $j$, and since all sector funds that cover the same factor offer exactly the same portfolio, the fine to each of them is zero. Furthermore, since there is a continuum of funds that offer the same holding, their competition will drive the management fees down to zero, which is stated in part 3 of Proposition 3.

Part 4 is a fund-of-funds idea. All investors hold one share at one and only one sector fund that covers factor $j$ (for all $j$ ), so their holdings through funds are $\left(H^{1}, H^{2}, \ldots, H^{Q}\right)^{\prime}$, which is exactly RAMP according to the definition of $H^{j}$. Part 5 is about investors' own information-based portfolios: by the information separation theorem, investors do not need any information about the financial market to construct their own informationbased portfolios. Part 4 and Part 5 together imply that in equilibrium, investors are effectively holding one share of RAMP and their own information-based portfolios, which are their optimal investment strategies in the equilibrium described in Proposition 1.

The two key assumptions underlying this implementation of RAMP with the mechanism $\Gamma$ are indeed plausible. The first is that there is competition among sector funds. This is needed because when there are sufficiently many sector funds who cover the same factor, competition can drive down the management fee, and the regulator can calculate the median share of each factor to implement the transfer system. This is similar to a necessary condition of Nash implementation in mechanism design problems: there must be at least three agents. In actual financial market, significant factors such as industry factors and regional factors, are usually covered by multiple index funds and ETFs. Hence, the assumption of sector funds' competition is plausible.

The other assumption is the disclosure of fund holdings. Without such a requirement, the regulator cannot compare funds' holdings and implement the transfer system. In practice, index funds are required to make quarterly disclosure about their asset holdings. ETFs are even more transparent and disclose holdings in a daily basis. 


\section{Extensions}

We now consider the robustness of our conclusions to allowing for a Gaussian prior or for heterogeneous risk aversions.

\subsection{Normal Prior}

In the model of Section 2, we assume for simplicity that investors hold a common uniform improper prior. We next verify that similar conclusions hold when we consider ambiguity averse investors' asset holdings with normal priors about asset payoffs. Formally, we assume that the asset payoffs are drawn from the distribution $F \sim \mathcal{N}\left(\bar{F}, V^{-1}\right)$, where $\bar{F}$ is the ex-ante mean and $V$ is the ex-ante precision matrix. Investors, however, may be ambiguous about such a distribution. So, in this case, a model should be characterized by $m=(\boldsymbol{\Sigma}, \boldsymbol{U}, W, \bar{F}, \boldsymbol{V})$.

We assume that in this case, the passive fund commits to offering a portfolio

$$
Y=\left[\boldsymbol{I}+\frac{1}{\rho^{2}}(\boldsymbol{\Sigma} \boldsymbol{U})^{-1}\right]^{-1} W+\rho\left[\boldsymbol{I}+\rho^{2} \Sigma \boldsymbol{U}\right]^{-1} V(\bar{F}-r P) .
$$

The portfolio $Y$ is the sum of $R A M P$ and a portfolio for contrarian trading. It can be shown to be the optimal portfolio in the setting without model uncertainty based on the prior and the price signal. However, since the prior and the price signal are not conditionally independent (because the prior is a determinant of the price signal), the two components that constitute the portfolio $Y$ are not information-separated.

Proposition 4 below shows that with the fund offering the portfolio $Y$, all investors will hold exactly one share of the fund, and any investor's overall risky asset holding is the same as that in the setting without model uncertainty.

Proposition 4. In the model with normal priors, when there is a passive fund that commits to offering the portfolio $Y$ specified in equation (18), there is an equilibrium in which

1. All investors will buy one share of the passive fund, and so $d_{i}^{*}=1$ for all $i \in[0,1]$; and

2. Any investor $i$ will hold an extra portfolio $D_{i}^{*}=\rho \Omega_{i}\left(S_{i}-r P\right)$.

We further analyze asset risk premia with the portfolio $Y$ being the pricing portfolio. While it is rather intractable to show that any asset's alpha is zero, Corollary 2 below argues that the portfolio $Y$ is the optimal portfolio choice of investors who do not have 
any private information. Since investors with no private information choose their portfolios based only on all public information (in this case, the prior and the price signal), $Y$ is mean-variance efficient conditional on all public signals.

Corollary 2. In the model with normal priors, when there is a passive fund that commits to offering the portfolio $Y$, any investor $i$ with $\boldsymbol{\Omega}_{i}=\mathbf{0}$ will choose the portfolio $Y$ in equilibrium.

\subsection{Heterogeneous Risk Aversions}

In the model of Section 2, investors share a same risk aversion coefficient $\rho$. This leads to investors' homogeneous holdings of the passive fund. Indeed, in the equilibrium characterized in Proposition 1, all investors hold one share of the passive fund. However, this raises the question of whether investors with different risk tolerances are willing to hold a single common passive fund, and if so, whether differences in risk tolerances, and investor unawareness of other investors' risk tolerances might result in heterogeneous holdings of the passive fund. To evaluate the robustness of our conclusions, we now extend the model to allow for heterogeneous risk tolerances.

We extend the model in Section 2 by assuming that any investor $i(i \in[0,1])$ has the risk aversion coefficient $\rho_{i}$. Here, $\rho_{i}$ is a continuous function of $i$. Let

$$
\bar{\rho}=\int_{0}^{1} \rho_{i} \mathrm{~d} i \quad \text { and } \bar{\Sigma}=\int_{0}^{1} \rho_{i} \Omega_{i} \mathrm{~d} i .
$$

Here, $\bar{\rho}$ is the average risk tolerance, and $\bar{\Sigma}$ is the average precision of investors' private information that is weighted by their risk tolerances. We assume that any investor $i$ knows $\rho_{i}$, but she does not know the distribution of $\rho_{j}$ or the average risk tolerance $\bar{\rho}$. Therefore, a financial market is characterized by $m=(\overline{\boldsymbol{\Sigma}}, \boldsymbol{U}, W, \bar{\rho})$. The passive fund cannot evaluate each individual investor's risk tolerance, but it has accurate information about the distribution of investors' risk tolerances; hence, it knows $\bar{\rho}$ and $\bar{\Sigma}$. Then, the passive fund offers the portfolio

$$
\bar{X}=\left[\bar{\rho} \mathbf{I}+(\overline{\boldsymbol{\Sigma}} \boldsymbol{U})^{-1}\right]^{-1} W .
$$

to all investors. Proposition 5 characterizes investors' equilibrium portfolios in such an extension.

Proposition 5. In the model with investors' heterogeneous risk tolerances, when there is a passive fund that commits to offering the portfolio $\bar{X}$ specified in equation (19), there is an equilibrium in which 
1. All investors will buy $\rho_{i}$ share of each passive fund, and so $d_{i}^{*}=\rho_{i}$ for all $i \in[0,1]$; and

2. Any investor $i$ will hold an extra portfolio $D_{i}^{*}=\rho_{i} \boldsymbol{\Omega}_{i}\left(S_{i}-r P\right)$.

It directly follows from Proposition 5 that with a passive fund offering the portfolio $\bar{X}$, investors hold the same portfolios as they do when they are not facing model uncertainty. Therefore, the conclusion of our baseline model that a wisely designed index can encourage investors to participate in the financial market and engage in index investing is robust.

On the other hand, Proposition 5 shows that the number of shares of the passive fund an investor holds depends on her risk tolerance. This is similar to that in the classic CAPM - all investors invest in the same index but the shares they hold the index fund depend on their risk tolerance.

\section{Concluding Remarks}

We study here two major roles played by market indexes, facilitating diversified investing, and providing an appropriate asset pricing benchmark, in a financial market with information asymmetry, model uncertainty, and ambiguity aversion. We show that with the Value-Weighted Market Portfolio (VWMP) as the available index investing vehicle, ambiguity averse investors do not invest in the index, which hinders diversification and risk sharing. This also implies that in comparison to a market without model uncertainty, informed investors need to hold extra positions to absorb a greater proportion of outstanding shares, including random supplies, and thus they will require ambiguity

premia in expected returns. So information asymmetry and ambiguity aversion lead to non-zero alphas of assets relative to $V W M P$ as the pricing portfolio.

We derive a new market index that adjusts market value weights to take into account the average precision of investor private signals and the precision of random supply of different assets, i.e., the amount of risk reduction investors obtain by conditioning on price as a signal. We call this index design the Risk-Adjusted Market Portfolio (RAMP). $R A M P$ is a defensive strategy in the sense that, relative to the value-weighted market, it underweights assets that are more volatile.

The ability of investors to invest in a RAMP index fund has major implications for equilibrium trading and asset pricing. In equilibrium, regardless of investors' heterogeneity in their subjective beliefs about the financial market, all investors hold the index 
as the passive (non-information-based) component of their portfolios. That is, RAMP induces investors to diversify by employing an index investment strategy. This improves the sharing of risk between investors who face model uncertainty about an asset and those who do not. In equilibrium, all investors' asset holdings are exactly the same as those in the economy without model uncertainty. Finally, the CAPM pricing relationship holds with respect to RAMP as the benchmark pricing portfolio, even though investors have asymmetric information and face model uncertainty. These results imply that delegation is a potential way to alleviate the inefficiency caused by model uncertainty.

These properties of RAMP derive from an information separation theorem in the financial market without model uncertainty. The information separation theorem says that to attain her optimal asset holdings, an investor first constructs an optimal portfolio based on each of her signals (i.e., price signal and private signal) and then sums all these optimal portfolios together. Then, in the setting with model uncertainty, when other investors are holding a passive fund offering RAMP and their information-based portfolios, in any possible financial market in her subjective belief support, an investor's optimal investment strategy is also to hold the fund and her own information-based portfolio. Therefore, providing RAMP to all investors facilitates their asset market participation and risk sharing.

The design of RAMP has important implications. First, because it underweights high volatility stocks, $R A M P$ is a defensive investing strategy. The investment strategy of following RAMP can also be viewed as a smart beta strategy, which is gaining increasing popularities. Second, since the RAMP fund can help promote investor participation and risk sharing, policy makers should consider whether to facilitate the offering of funds that approximate it. This policy implication may be effective especially in emerging countries where the regulatory powers of government may give it advantages for collecting information for estimating the relevant parameter values of RAMP. Furthermore, educators or policymakers can take steps to inform investors about concepts of optimal risk sharing, and may consider making RAMP available to investors in retirement investing plans. 


\section{A Omitted Proofs}

Proof of Proposition 1:

We first verify that the market clearing condition holds. Each investor $i$ 's effective risky assets holding is

$$
d_{i}^{*} X+D_{i}^{*}=\left[\boldsymbol{I}+\frac{1}{\rho^{2}}(\Sigma \boldsymbol{U})^{-1}\right]^{-1} W+\rho \boldsymbol{\Omega}_{i}\left(S_{i}-r P\right) .
$$

Then, using the pricing function (equation (8)), the aggregate demand can be calculated as

$$
\begin{aligned}
& \int_{0}^{1}\left(d_{i}^{*} X+D_{i}^{*}\right) \mathrm{d} i \\
= & {\left[\boldsymbol{I}+\frac{1}{\rho^{2}}(\boldsymbol{\Sigma} \boldsymbol{U})^{-1}\right]^{-1} W+\rho \boldsymbol{\Sigma}(F-r P) } \\
= & {\left[\boldsymbol{I}+\frac{1}{\rho^{2}}(\boldsymbol{\Sigma} \boldsymbol{U})^{-1}\right]^{-1} W+\rho \boldsymbol{\Sigma}\left(\frac{1}{\rho}\left(\boldsymbol{\Sigma}+\rho^{2} \boldsymbol{\Sigma} \boldsymbol{U} \boldsymbol{\Sigma}\right)^{-1} W+\frac{1}{\rho} \boldsymbol{\Sigma}^{-1} Z\right) } \\
= & {\left[\boldsymbol{I}+\frac{1}{\rho^{2}}(\boldsymbol{\Sigma} \boldsymbol{U})^{-1}\right]^{-1} W+\left[\boldsymbol{I}+\rho^{2} \boldsymbol{\Sigma} \boldsymbol{U}\right]^{-1} W+Z } \\
= & \rho^{2} \boldsymbol{\Sigma} \boldsymbol{U}\left[\boldsymbol{I}+\rho^{2} \boldsymbol{\Sigma} \boldsymbol{U}\right]^{-1} W+\left[\boldsymbol{I}+\rho^{2} \boldsymbol{\Sigma} \boldsymbol{U}\right]^{-1} W+Z \\
= & W+Z .
\end{aligned}
$$

Therefore, the market clears.

We then show that when all other investors choose the prescribed investment strategies, any investor $i$ will not make a unilateral deviation from the prescribed investment strategy either. That is, if $d_{j}^{*}=1$ and $D_{j}^{*}=\rho \Omega_{j}\left(S_{j}-r P\right)$ for all $j \in[0,1] \backslash\{i\}$, then $d_{i}^{*}=1$ and $D_{i}^{*}=\rho \Omega_{i}\left(S_{i}-r P\right)$.

In our model, any investor understands that she is small and so her trading will not affect the aggregate demand. Hence, for a fixed financial market $m_{i} \in \mathcal{M}_{i}$, investor $i$ knows that all other investors' investment strategies lead to the aggregate asset demand

$$
\begin{aligned}
& \int_{0}^{1}\left(d_{j}^{*} X+D_{j}^{*}\right) \mathrm{d} j \\
= & {\left[\boldsymbol{I}+\frac{1}{\rho^{2}}(\boldsymbol{\Sigma} \boldsymbol{U})^{-1}\right]^{-1} W+\int_{0}^{1} \rho \boldsymbol{\Omega}_{j}\left(S_{j}-r P\right) \mathrm{d} j } \\
= & {\left[\boldsymbol{I}+\frac{1}{\rho^{2}}(\boldsymbol{\Sigma} \boldsymbol{U})^{-1}\right]^{-1} W+\rho \boldsymbol{\Sigma} F-\rho r P . }
\end{aligned}
$$


Here, $(\boldsymbol{\Sigma}, \boldsymbol{U}, W)=m_{i}$.

Then, the market clearing in the financial market $m_{i}$ implies

$$
\begin{aligned}
& {\left[\boldsymbol{I}+\frac{1}{\rho^{2}}(\boldsymbol{\Sigma} \boldsymbol{U})^{-1}\right]^{-1} W+\rho \boldsymbol{\Sigma} F-\rho r P=W+Z } \\
\Rightarrow & \rho \boldsymbol{\Sigma} F=\left[\boldsymbol{I}-\left(\boldsymbol{I}+\frac{1}{\rho^{2}}(\boldsymbol{\Sigma} \boldsymbol{U})^{-1}\right)^{-1}\right] W+\rho r P+Z \\
\Rightarrow & F=\frac{1}{\rho}\left[\boldsymbol{\Sigma}^{-1}-\left(\boldsymbol{\Sigma}+\frac{1}{\rho^{2}} \boldsymbol{U}^{-1}\right)^{-1}\right] W+r \boldsymbol{\Sigma}^{-1} P+\frac{1}{\rho} \boldsymbol{\Sigma}^{-1} Z .
\end{aligned}
$$

Hence, conditional on the price, investor $i$ 's belief over $F$ is

$$
F \mid P \sim \mathcal{N}\left(\frac{1}{\rho}\left[\Sigma^{-1}-\left(\boldsymbol{\Sigma}+\frac{1}{\rho^{2}} \boldsymbol{U}^{-1}\right)^{-1}\right] W+r \boldsymbol{\Sigma}^{-1} P, \frac{1}{\rho^{2}} \boldsymbol{\Sigma}^{-1} \boldsymbol{U}^{-1} \boldsymbol{\Sigma}^{-1}\right) .
$$

Then, investor $i$ 's optimal portfolio in the financial market $m_{i}$ is

$$
\begin{aligned}
& \rho \mathbb{V}\left(F \mid P, S_{i}\right)^{-1}\left(\mathbb{E}\left(F \mid P, S_{i}\right)-r P\right) \\
= & {\left[\boldsymbol{I}+\frac{1}{\rho^{2}}(\boldsymbol{\Sigma} \boldsymbol{U})^{-1}\right]^{-1} W+\rho \boldsymbol{\Omega}_{i}\left(S_{i}-r P\right) } \\
= & X+D_{i}^{*} .
\end{aligned}
$$

That is, given $d_{j}^{*}=1$ and $D_{j}^{*}=\rho \boldsymbol{\Omega}_{j}\left(S_{j}-r P\right)$ for all $j \in[0,1] \backslash\{i\}$, investor $i^{\prime}$ s optimal portfolio in any $m_{i} \in \mathcal{M}_{i}$ is $\left(d_{i}^{*}, D_{i}^{*}\right)=\left(1, \rho \boldsymbol{\Omega}_{i}\left(S_{i}-r P\right)\right)$.

Note that $\left(d_{i}^{*}, D_{i}^{*}\right)$ is independent of $m_{i}$, so we have

$$
\begin{aligned}
& \inf _{m_{i} \in \mathcal{M}_{i}} \max _{\left(d_{i}, D_{i}\right)} U\left(m,\left(d_{i}, D_{i}\right)\right) \\
= & \inf _{m_{i} \in \mathcal{M}_{i}} U\left(m,\left(d_{i}^{*}, D_{i}^{*}\right)\right) \\
\leq & \max _{\left(d_{i}, D_{i}\right)} \inf _{m_{i} \in \mathcal{M}_{i}} U\left(m,\left(d_{i}, D_{i}\right)\right) .
\end{aligned}
$$

Since generally

$$
\inf _{m_{i} \in \mathcal{M}_{i}} \max _{\left(d_{i}, D_{i}\right)} U\left(m,\left(d_{i}, D_{i}\right)\right) \geq \max _{\left(d_{i}, D_{i}\right)} \inf _{m_{i} \in \mathcal{M}_{i}} U\left(m,\left(d_{i}, D_{i}\right)\right),
$$

we have

$$
\inf _{m_{i} \in \mathcal{M}_{i}} \max _{\left(d_{i}, D_{i}\right)} U\left(m,\left(d_{i}, D_{i}\right)\right)=\max _{\left(d_{i}, D_{i}\right)} \inf _{m_{i} \in \mathcal{M}_{i}} U\left(m,\left(d_{i}, D_{i}\right)\right) .
$$


Hence, $\left(d_{i}^{*}, D_{i}^{*}\right)$ is a solution to $\max _{\left(d_{i}, D_{i}\right)} \inf _{m_{i} \in \mathcal{M}_{i}} U\left(m,\left(d_{i}, D_{i}\right)\right)$, implying that investor $i$ does not have incentives to deviate from the prescribed investment strategy.

Q.E.D.

Proof of Proposition 2:

By equations (14), (15), and (16), we have

$$
\begin{aligned}
& \frac{\frac{1}{P^{\prime} X} \operatorname{diag}(P)^{-1} C U^{-1} C X}{\left(\frac{1}{P^{\prime} X}\right)^{2} X^{\prime} C U^{-1} C X} \frac{X^{\prime} A}{P^{\prime} X} \\
= & \frac{\operatorname{diag}(P)^{-1} C U^{-1} C X}{X^{\prime} C U^{-1} C X} X^{\prime} A .
\end{aligned}
$$

This is the RHS of the Security Market Line relation. We want to show that this equals the difference between the risky assets' rates of return and the riskfree asset's rate of return, which is shown to be $\operatorname{diag}(P)^{-1} A$ from equation (13).

Then, we have

$$
\begin{aligned}
& \frac{\operatorname{diag}(P)^{-1} \boldsymbol{C} \boldsymbol{U}^{-1} \boldsymbol{C} X}{X^{\prime} \boldsymbol{C} \boldsymbol{U}^{-1} \boldsymbol{C} X} X^{\prime} A=\operatorname{diag}(P)^{-1} A \\
\Leftrightarrow & \operatorname{diag}(P)^{-1} \boldsymbol{C} \boldsymbol{U}^{-1} \boldsymbol{C} X X^{\prime} A=\operatorname{diag}(P)^{-1} A X^{\prime} \boldsymbol{C} \boldsymbol{U}^{-1} \boldsymbol{C} X \\
\Leftrightarrow & \boldsymbol{C} \boldsymbol{U}^{-1} \boldsymbol{C} X X^{\prime} A=A X^{\prime} \boldsymbol{C} \boldsymbol{U}^{-1} \boldsymbol{C} X .
\end{aligned}
$$

The last equation holds because $X=\rho\left(\boldsymbol{C} \boldsymbol{U}^{-1} \boldsymbol{C}\right)^{-1} A$ and $\left(\boldsymbol{C} \boldsymbol{U}^{-1} \boldsymbol{C}\right)^{-1}$ is a symmetric matrix.

Q.E.D.

Proof of Proposition 3:

Given that $\mathcal{A}_{j}$ is just the group of factor- $j$-uninformed investors, the strategy profile described in Part 1 and Part 2 implies that $\widehat{H}^{j}=H^{j}$. Then, if any investor $k$ offers $H_{k}^{j} \neq H^{j}$, the regulator imposes a fine $\left|H_{k}^{j}-H^{j}\right| B>0$. Hence, such a deviation is not profitable. Therefore, no fund will deviate from the portfolio it offers. Part 3 is simply due to the competition among all sector funds that covers the same factor. 
Part 4 and Part 5 imply that any investor's asset holding is exactly the same as in Proposition 1. Therefore, by the proof of Proposition 1, no investor wants to deviate. This completes the proof.

Q.E.D.

Proof of Proposition 4:

The proof is similar to that of Proposition 1 . Consider the strategy profile that $\left(d_{i}^{*}, D_{i}^{*}\right)=$ $\left(1, \rho \boldsymbol{\Omega}_{i}\left(S_{i}-r P\right)\right)$ for all $i \in[0,1]$. We argue that no investor wants to make a unilateral deviation.

Given all other investors' investment strategy, in a model in investor $i$ 's subjective belief $m_{i}=(\boldsymbol{\Sigma}, \boldsymbol{U}, W, \bar{F}, \boldsymbol{V}) \in \mathcal{M}_{i}$, the market clearing condition implies that

$F=\frac{1}{\rho} \Sigma^{-1}\left[\boldsymbol{I}-\left(\boldsymbol{I}+\frac{1}{\rho^{2}}(\boldsymbol{\Sigma} \boldsymbol{U})^{-1}\right)^{-1}\right] W-\boldsymbol{\Sigma}^{-1}\left[\boldsymbol{I}+\rho^{2} \boldsymbol{\Sigma} \boldsymbol{U}\right]^{-1} V(\bar{F}-r P)+r P+\frac{1}{\rho} \boldsymbol{\Sigma}^{-1} Z$.

Hence, $F \mid P$ is normally distributed with mean

$$
\frac{1}{\rho} \boldsymbol{\Sigma}^{-1}\left[\boldsymbol{I}-\left(\boldsymbol{I}+\frac{1}{\rho^{2}}(\boldsymbol{\Sigma} \boldsymbol{U})^{-1}\right)^{-1}\right] W-\boldsymbol{\Sigma}^{-1}\left[\boldsymbol{I}+\rho^{2} \boldsymbol{\Sigma} \boldsymbol{U}\right]^{-1} \boldsymbol{V}(\bar{F}-r P)+r P
$$

and the precision

$$
\rho^{2} \Sigma U \Sigma \text {. }
$$

Therefore, conditional on the prior, and the asset prices, and her own private signals (in model $m_{i}$ ), investor $i$ 's optimal portfolio is

$$
\begin{aligned}
& {\left[\boldsymbol{I}+\frac{1}{\rho^{2}}(\boldsymbol{\Sigma} \boldsymbol{U})^{-1}\right]^{-1} W+\rho\left[\boldsymbol{I}+\rho^{2} \boldsymbol{\Sigma} \boldsymbol{U}\right]^{-1} V(\bar{F}-r P)+\rho \boldsymbol{\Omega}_{i}\left(S_{i}-r P\right) } \\
= & Y+D_{i}^{*},
\end{aligned}
$$

implying that $\left(d_{i}^{*}, D_{i}^{*}\right)=\left(1, \rho \boldsymbol{\Omega}_{i}\left(S_{i}-r P\right)\right)$ is optimal in the model $m_{i}$.

Furthermore, $\left(d_{i}^{*}, D_{i}^{*}\right)$ is independent of $m_{i}$. Hence, by the exactly same argument at the end of the proof of Proposition 1, we show that $\left(d_{i}^{*}, D_{i}^{*}\right)$ is the solution to the investor $i$ 's maxmin problem, provided that all other investors trade as prescribed.

Q.E.D.

Proof of Proposition 5: 
The proof is also similar to that of Proposition 1. For a given model $m_{i}=(\overline{\boldsymbol{\Sigma}}, \boldsymbol{U}, W, \bar{\rho})$, when all other investors trade as prescribed, investor $i$ believes that the market clearing condition is

$$
\int_{0}^{1}\left(\rho_{j}\left[\bar{\rho} \boldsymbol{I}+(\overline{\boldsymbol{\Sigma}} \boldsymbol{U})^{-1}\right]^{-1} W+\rho_{j} \boldsymbol{\Omega}_{j}\left(S_{j}-r P\right)\right) \mathrm{d} j=W+Z,
$$

which implies that the pricing function is

$$
F=\overline{\boldsymbol{\Sigma}}^{-1}\left[I-\bar{\rho}\left[\bar{\rho} \boldsymbol{I}+(\overline{\boldsymbol{\Sigma}} \boldsymbol{U})^{-1}\right]^{-1}\right] W+r p+\overline{\boldsymbol{\Sigma}}^{-1} Z .
$$

Hence, the asset payoffs conditional on asset prices have the distribution

$$
F \mid P \sim \mathcal{N}\left(\overline{\boldsymbol{\Sigma}}^{-1}\left[I-\bar{\rho}\left[\bar{\rho} \boldsymbol{I}+(\overline{\boldsymbol{\Sigma}} \boldsymbol{U})^{-1}\right]^{-1}\right] W+r p, \overline{\boldsymbol{\Sigma}}^{-1} \boldsymbol{U}^{-1} \overline{\boldsymbol{\Sigma}}^{-1}\right) .
$$

Then, investor $i$ 's optimal portfolio choice in the financial market $m_{i}$ is

$$
\begin{aligned}
& \rho_{i} \mathbb{V}\left(F \mid P, S_{i}\right)^{-1}\left[\mathbb{E}\left(F \mid P, S_{i}\right)-r p\right] \\
= & \rho_{i}\left[\bar{\rho} \boldsymbol{I}+(\overline{\boldsymbol{\Sigma}} \boldsymbol{U})^{-1}\right]^{-1} W+\rho_{i} \boldsymbol{\Omega}_{i}\left(S_{i}-r P\right) \\
= & \rho_{i} \bar{X}+\rho_{i} \boldsymbol{\Omega}_{i}\left(S_{i}-r P\right) .
\end{aligned}
$$

That is, investor $i$ 's optimal investment strategy in the perceived financial market $m_{i}$ is $\left(d_{i}^{*}, D_{i}^{*}\right)=\left(\rho_{i}, \rho_{i} \boldsymbol{\Omega}_{i}\left(S_{i}-r P\right)\right)$. Because such an investment strategy is independent of $m_{i}$, by the same argument at the end of the proof of Proposition 1, we can show that investor $i$ 's optimal investment strategy is $\left(d_{i}^{*}, D_{i}^{*}\right)$.

Therefore, given investor $j \in[0,1] \backslash\{i\}$ employs the investment strategy $\left(d_{j}^{*}, D_{j}^{*}\right)=$ $\left(\rho_{j}, \rho_{j} \Omega_{j}\left(S_{j}-r P\right)\right)$, investor $i$ will not deviate, proving that the strategy under consideration is an equilibrium.

Q.E.D. 


\section{B A Benchmark: The Value-Weighted Market Portfolio}

In this appendix, we discuss the investors' equilibrium asset holdings and the asset pricing implications when the fund is offering the investors with the value-weighted market portfolio (VWMP); formally, we assume that $X=W$. We show that ambiguity averse investors are not willing to hold a fund offering VWMP as the passive (noninformational) index component of their portfolios, and that VWMP is not the appropriate benchmark portfolio for pricing assets. This establishes a benchmark for our analysis when the passive fund is offering RAMP.

To keep such a benchmark model tractable, we assume that all assets are independent. That is, $\Omega_{i}$ is diagonal for all $i \in[0,1]$. Then, investor $i$ is an informed investor of asset $n$ if and only if the $n^{\text {th }}$ diagonal entry of $\boldsymbol{\Omega}_{i}$ is strictly positive. Let $\lambda_{n}$ be the measure of informed investors of asset $n$; we assume that $\lambda_{n} \in(0,1)$, for all $n \in \mathcal{Q}$. Let $\operatorname{diag}(\lambda)$ be the $N \times N$ diagonal matrix with the $n^{\text {th }}$ diagonal entry being $\lambda_{n}$.

For simplicity, we assume that the private signals of all informed investors of asset $n$ have the same precision $\kappa_{n}>0$. Let $\Omega$ be the $N \times N$ diagonal matrix with the $n^{\text {th }}$ diagonal entry being $\kappa_{n}$. Letting $\Sigma$ be the matrix of the average precision of private signals, we have

$$
\Sigma=\int_{0}^{1} \boldsymbol{\Omega}_{i} \mathrm{~d} i=\mathbf{\Omega} \operatorname{diag}(\lambda)
$$

Because assets are independent, $U$ is also diagonal. We focus on the case that all model parameters are commonly known among investors except $U$. We assume that for each asset $n$, a subset of uninformed investors do not know $u_{n}$. We say that such a group of investors are subject to model uncertainty (or are ambiguous) about asset $n$. Any investor $i$ who is ambiguous about asset $n$ will have her own subjective prior belief about $u_{n}$ with the support $\left(0, \bar{u}_{n}^{i}\right)$, where $\bar{u}_{n}^{i}>0$. So we allow different investors who are ambiguous about a particular asset $n$ to have different supports of their beliefs about $u_{n}$. Let $\mathcal{U}_{i}$ be the set of all possible subjective beliefs of investor $i$ about $U$, let $\boldsymbol{U}_{i}$ be a typical element in $\mathcal{U}_{i}$, and let $\underline{\boldsymbol{U}}_{i}$ be the lower bound of $\mathcal{U}_{i}$.

Let the measure of the group of investors who are ambiguous about $n$ be $1-q_{n} \in$ $\left(0,1-\lambda_{n}\right)$. Let $Q$ be the $N \times N$ diagonal matrix with the $n^{\text {th }}$ diagonal entry being $q_{n}$. For simplicity, we assume that an investor who is ambiguous about asset $n$ is also uninformed about asset $n$. However, an investor who is uninformed about asset $n$ may know $u_{n}$ and so is not ambiguous about asset $n$. 
Each investor $i$ 's decision problem is then

$$
\max _{d_{i}, D_{i}} \inf _{U_{i} \in \mathcal{U}_{i}} \mathbb{E}_{i}\left[-\exp \left(-\frac{\Pi_{i}}{\rho}\right)\right] .
$$

\section{B.1 Equilibrium Asset Holdings}

Since the composition of VWMP is commonly known, even if no fund is available that offers VWMP, an investor can attain the same effective risky asset holdings by directly trading individual assets only. So an investor's optimal risky asset holdings are the same regardless of whether this passive fund is available. As a result, in order to analyze investors' equilibrium asset holdings when VWMP is publicly offered, we can first consider an economy without VWMP.

Investor $i$ is risk averse, so she only holds a non-zero position of asset $n$, if her subjective belief of asset $n$ 's payoff has a finite variance, conditional on her information. When investor $i$ is uninformed about asset $n$, however, she has neither prior information nor private information about the payoff of asset $n$. Hence, she estimates the payoff based on only the price, which partially aggregates informed investors' private information. Since the precision of asset $n^{\prime}$ s random supply, $u_{n}$, is strictly positive (no matter how small it is), if investor $i$ knows $u_{n}$, her belief of asset $n$ 's payoff has a finite variance and, therefore, she will hold a non-zero position of asset $n$.

On the other hand, if investor $i$ is subject to model uncertainty about asset $n$, she does not know the precision of asset $n$ 's random supply. By assumption, investor $i$ 's subjective prior about $u_{n}$ has the support $\left(0, \bar{u}_{n}^{i}\right)$. Since all random variables in the model are normally distributed, observing the asset price does not change the support of investor $i$ 's belief about $u_{n}$, although investor $i$ may extract some information about $u_{n}$ from asset $n$ 's price. Hence, the worst-case scenario is independent of asset $n$ 's price. Specifically, when the precision of the random supply is arbitrarily close to zero, price becomes almost uninformative. So as investor $i$ considers the worst-case scenario in making the investment decision, she focuses on the possibility that the true $u_{n}$ is very close to 0 . For any non-zero position of asset $n$, as the price becomes almost uninformative, the payoff variance conditional upon investor $i$ 's information diverges to infinity. So holding a non-zero position is extremely risky in the worst-case scenario. To avoid this risk, investor $i$ optimally chooses a zero position. Lemma 1 below summarizes the argument above. 
Lemma 1. An investor $i$ who is ambiguous about asset $n$ optimally holds a zero position in it.

Proof of Lemma 1:

Because investor $i$ is ambiguous about asset $n$, by assumption, she does not have private signal about asset $n$ 's payoff; that is, $\kappa_{i}=0$. Hence, investor $i$ 's only information about the distribution of asset $n$ 's payoff is its price, which may partially aggregate informed investors' private signals. Suppose the uninformed investors' aggregate demand for asset $n$ is $\left(1-\lambda_{n}\right) D\left(p_{n}\right)$. Since uninformed investors do not observe $u_{n}, D\left(p_{n}\right)$ is not a function of $u_{n}$.

Given any $P$ and any $u_{n} \in\left(0, \bar{u}_{n}^{i}\right)$, we derive investor $i^{\prime}$ s expected utility conditional on $P_{n}$ as follows. Suppose asset $n^{\prime}$ s pricing function in a linear equilibrium is

$$
f_{n}=a+b p_{n}+c z_{n}
$$

where $a, b$, and $c$ are undetermined parameters. Since informed investors know $u_{n}$, they can extract information from the price without any ambiguity. Therefore, any informed investor $j$ 's demand is

$$
D_{j}=\rho\left[\kappa_{n} s_{j}+\frac{u_{n}}{c^{2}} a+\frac{u_{n}}{c^{2}}(b-r) p_{n}-r \kappa_{n} p_{n}\right] .
$$

Then, the informed investors' aggregate demand will be

$$
\lambda_{n} \rho\left[\kappa_{n} f_{n}+\frac{u_{n}}{c^{2}} a+\frac{u_{n}}{c^{2}}(b-r) p_{n}-r \kappa_{n} p_{n}\right] .
$$

Then, the market clearing condition implies that

$$
\lambda_{n} \rho\left[\kappa_{n} f_{n}+\frac{u_{n}}{c^{2}} a+\frac{u_{n}}{c^{2}}(b-r) p_{n}-r \kappa_{n} p_{n}\right]+\left(1-\lambda_{n}\right) D\left(P_{n}\right)=w_{n}+z_{n} .
$$

Matching the coefficient of the market clearing condition and the pricing function, we have

$$
\begin{aligned}
a & =\frac{w_{n}}{\lambda_{n} \kappa_{n} \rho}-\frac{u_{n}}{c^{2} \kappa_{n}} a \\
b p_{n} & =-\frac{\left(1-\lambda_{n}\right) D\left(p_{n}\right)}{\lambda_{n} \kappa_{n} \rho}-\frac{u_{n}}{c^{2} \kappa_{n}}(b-r) p_{n}+r p_{n} \\
c & =\frac{1}{\lambda_{n} \kappa_{n} \rho}
\end{aligned}
$$


Therefore, for any given $u_{n} \in\left(0, \bar{u}_{n}^{i}\right)$, conditional on the price $P_{n},\left|\mathbb{E}\left(f_{n}-r p_{n} \mid p_{n}\right)\right|<$ $+\infty$. On the other hand, the variance of asset $n$ 's payoff conditional on $p_{n}$ is

$$
\mathbb{V}\left(f_{n} \mid p_{n}\right)=c^{2} u_{n}^{-1},
$$

which diverges to $+\infty$ as $u_{n}$ goes to 0 . Hence, any non-zero position $D_{i}$ of asset $n$ brings investor $i$ a utility

$$
-\exp \left(-\frac{1}{\rho} w_{i} r p_{n}\right) \exp \left[-\frac{1}{\rho} D_{i} \mathbb{E}\left(f_{n}-r p_{n} \mid p_{n}\right)+\frac{D_{i}^{2}}{2 \rho^{2}} \mathbb{V}\left(f_{n} \mid p_{n}\right)\right],
$$

which goes to $-\infty$ as $u_{n}$ goes to 0 . Therefore, if investor $i$ is ambiguous about asset $n$, investor $i$ will hold a zero position of asset $n$.

Q.E.D.

We now analyze the investors' equilibrium asset holdings. The model is similar to the rational expectations equilibrium model with multiple risky assets (Admati 1985). The key difference is that for each asset $n$, there are $1-q_{n}$ measure investors who will hold a zero position (by Lemma 1). Proposition 6 below characterizes a linear rational expectations equilibrium. Recall that since the composition of VWMP is commonly known, whether or not such a portfolio is offered by the passive fund, investors will have the same effective risky asset holdings.

Proposition 6. In the model where the passive fund offers VWMP (formally, $X=W$ ), there exists a linear equilibrium with the pricing function

$$
P=B_{V}^{-1}\left[F-A_{V}-C_{V} Z\right]
$$

where

$$
\begin{aligned}
A_{V} & =\frac{1}{\rho}\left[\rho^{2}(\Sigma Q U \boldsymbol{\Sigma} \boldsymbol{\Sigma})+\boldsymbol{\Sigma}\right]^{-1} W \\
\boldsymbol{B}_{V} & =r \boldsymbol{I} \\
C_{V} & =\frac{1}{\rho} \boldsymbol{\Sigma}^{-1} .
\end{aligned}
$$

Any investor i's effective risky asset holding is

$$
d_{i} X+D_{i}=\lim _{\boldsymbol{U}_{i} \rightarrow \underline{\boldsymbol{U}}_{i}}\left[\boldsymbol{I}+\frac{1}{\rho^{2}}\left(\boldsymbol{\Sigma} \boldsymbol{U}_{i}\right)^{-1}\right]^{-1} W+\rho \boldsymbol{\Omega}_{i}\left(S_{i}-r P\right)
$$


Proof of Proposition 6:

We assume that the pricing function can be written as

$$
F=A_{V}+B_{V} P+C_{V} Z,
$$

where $B_{V}$ is nonsingular. Then, conditional on the asset prices $P$, an investor $i$ 's updated belief about asset payoffs is

$$
F \mid P \sim \mathcal{N}\left(A_{V}+\boldsymbol{B}_{V} P, \boldsymbol{C}_{V}^{\prime} \boldsymbol{U}_{i}^{-1} \boldsymbol{C}_{V}\right),
$$

where $\mathcal{U}_{i} \in \mathcal{U}_{i}$

Then, each investor $i$ 's optimal asset holdings are

$$
d_{i} X+D_{i}=\rho\left\{\left(\boldsymbol{C}_{V} \boldsymbol{U}_{i}^{-1} \boldsymbol{C}_{V}^{\prime}\right)^{-1}\left(\boldsymbol{B}_{V}-r \boldsymbol{I}\right)-r \boldsymbol{\Omega}_{i}\right\} P+\rho \boldsymbol{\Omega}_{i} S_{i}+\rho\left[\left(\boldsymbol{C} \boldsymbol{U}^{-1} \boldsymbol{C}^{\prime}\right)^{-1} A_{V}\right] .
$$

It follows from Lemma 1 that if investor $i$ is ambiguous about asset $n$, her holding of asset $n$ is zero. Then, aggregating all investors' effective asset holdings and applying the market clearing condition yield

$$
\begin{aligned}
D & =\rho\left[\left(\boldsymbol{C}_{V}^{\prime}\right)^{-1} Q \boldsymbol{U}\left(\boldsymbol{C}_{V}\right)^{-1} A_{V}\right]+\rho \boldsymbol{\Sigma} F+\rho\left[\left(\boldsymbol{C}_{V}^{\prime}\right)^{-1} Q U\left(\boldsymbol{C}_{V}\right)^{-1}\left(\boldsymbol{B}_{V}-r \boldsymbol{I}-r \boldsymbol{\Sigma}\right)\right] P \\
& =W+Z
\end{aligned}
$$

Therefore, by matching coefficients, we have

$$
\begin{aligned}
& C_{V}=\frac{1}{\rho} \Sigma^{-1} \\
& \boldsymbol{B}_{V}=r \boldsymbol{I} \\
& A_{V}=\frac{1}{\rho}\left[\rho^{2} \Sigma Q U \Sigma+\Sigma\right]^{-1} W .
\end{aligned}
$$

Substituting these parameters into the pricing function and the individual investor's asset holding function, we get Proposition 6.

Q.E.D.

Equations (23) and (24) show that for each risky asset $n$, the measure of investors who know the precision of its random supply affects its equilibrium price. In particular, $Q U$ is the matrix of the average precisions of asset random supplies in the investors' subjective "worst-case scenarios," which positively affect the asset prices. Hence, ceteris 
paribus, if $q_{k}>q_{n}$, the equilibrium price of asset $k$ is greater than that of asset $n$. Intuitively, when $q_{k}>q_{n}$, on average the subjective worst case for $k$ is not as bad as for $n$, so the demand function for asset $k$ is higher than the demand function for asset $n$. So when both assets have the same supply, asset $k^{\prime}$ s price is higher than that of asset $n$.

Equation (27) characterizes investor $i$ 's effective risky asset holdings in equilibrium. For each asset $n$, if investor $i$ knows the precision of its random supply, she will hold a position based on the equilibrium price. Formally, in such a case, the $n^{\text {th }}$ diagonal entry of $\underline{U}_{i}$ is $u_{n}>0$; hence, the first term in equation (27) is positive. Furthermore, if such an investor receives a private signal about asset $n^{\prime}$ s payoff, the $n^{\text {th }}$ diagonal entry of $\boldsymbol{\Omega}_{i}$ is $\kappa_{n}>0$, and so the second term is also positive.

At the other extreme, if investor $i$ is ambiguous about asset $n$, both the $n^{\text {th }}$ diagonal entry of $\underline{\boldsymbol{U}}_{i}$ and the $n^{\text {th }}$ diagonal entry of $\boldsymbol{\Omega}_{i}$ are zero, implying that investor $i$ holds a zero position of asset $n$. Therefore, even with a passive fund offering VWMP, ambiguity averse investors will not participate in some assets' markets. As a result, VWMP is not effective in encouraging ambiguity averse investors to hold better-diversified portfolios.

\section{B.2 Asset Pricing with VWMP}

We next analyze asset risk premia to see if VWMP is, as in the CAPM, the relevant pricing portfolio. Given any realized equilibrium price $P$, the volatility of asset payoffs derives from the supply shock only. Let $\operatorname{diag}(P)$ be an $N \times N$ diagonal matrix, whose $n^{\text {th }}$ diagonal element is the $n^{\text {th }}$ element of the vector $P$. Generically, as no asset has a zero price, $\operatorname{diag}(P)$ is invertible. Then, by the definition of $\operatorname{diag}(P)$,

$$
\operatorname{diag}(P)^{-1} P=\mathbb{1},
$$

where $\mathbb{1}=(1,1, \ldots, 1)^{\prime}$. From equation (23), we can calculate the difference between individual assets' expected rates of return and the riskfree rate as

$$
\operatorname{diag}(P)^{-1} \mathbb{E}(F)-r \mathbb{1}=\operatorname{diag}(P)^{-1} A_{V},
$$

where $A_{V}$ is characterized in equation (24), and the expectation is taken conditional on the asset prices.

Since the pricing portfolio is VWMP, we calculate the market capitalization weights for individual assets as

$$
\omega_{V}=\frac{\operatorname{diag}(P) W}{P^{\prime} W} .
$$


Then, the variance of $V W M P$ is

$$
\operatorname{Var}\left(R_{V}\right)=\left(\frac{1}{P^{\prime} W}\right)^{2} W^{\prime} \boldsymbol{C}_{V} \boldsymbol{U}^{-1} \boldsymbol{C}_{V} W,
$$

and the covariances between individual assets and VWMP are

$$
\operatorname{Cov}\left(R, R_{V}\right)=\frac{1}{P^{\prime} W} \operatorname{diag}(P)^{-1} \boldsymbol{C}_{V} \boldsymbol{U}^{-1} \boldsymbol{C}_{V} .
$$

Here, $C_{V}$ is characterized in equation (26).

Therefore, when the pricing portfolio is VWMP, the assets' betas are

$$
\beta_{V}=\frac{\operatorname{Cov}\left(R, R_{V}\right)}{\operatorname{Var}\left(R_{V}\right)}=P^{\prime} W \frac{\operatorname{diag}(P)^{-1} \boldsymbol{C}_{V} \boldsymbol{U}^{-1} \boldsymbol{C}_{V}}{W^{\prime} \boldsymbol{C}_{V} \boldsymbol{U}^{-1} \boldsymbol{C}_{V} W},
$$

and their alphas are

$$
\alpha_{V}=\operatorname{diag}(P)^{-1} A_{V}-\beta_{V}\left[\mathbb{E}\left(R_{V}\right)-r\right]=\operatorname{diag}(P)^{-1}\left[\boldsymbol{I}-\frac{\boldsymbol{C}_{V} \boldsymbol{U}^{-1} \boldsymbol{C}_{V} W W^{\prime}}{W^{\prime} \boldsymbol{C}_{V} \boldsymbol{U}^{-1} \boldsymbol{C}_{V} W}\right] A_{V} .
$$

Simple algebra verifies that VWMP does not successfully price assets in the capital market.

Proposition 7. With VWMP being the pricing portfolio, the assets' alphas are not equal to zero.

\section{Proof of Proposition 7:}

From equation (35), individual assets' alphas are

$$
\alpha_{V}=\operatorname{diag}(P)^{-1}\left[\boldsymbol{I}-\frac{\boldsymbol{C}_{V} \boldsymbol{U}^{-1} \boldsymbol{C}_{V} W W^{\prime}}{W^{\prime} \boldsymbol{C}_{V} \boldsymbol{U}^{-1} \boldsymbol{C}_{V} W}\right] A_{V} .
$$

Because $\frac{\mathcal{C}_{V} \boldsymbol{U}^{-1} \mathcal{C}_{V} W W^{\prime}}{W^{\prime} C_{V} U^{-1} C_{V} W} \neq I, \alpha_{V}=0$ if and only if $A_{V}$ is an eigenvector of $\frac{\mathcal{C}_{V} U^{-1} C_{V} W W^{\prime}}{W^{\prime} C_{V} U^{-1} C_{V} W}$ with the associated eigenvalue 1 . Therefore, $A_{V}$ should not be a function of $Q$, since $I-\frac{C_{V} U^{-1} C_{V} W W^{\prime}}{W^{\prime} C_{V} U^{-1} C_{V} W}$ is not a function of $Q$. However, it follows from Proposition 6 that $A_{V}=\frac{1}{\rho}\left[\rho^{2} \Sigma Q U \Sigma+\Sigma\right]^{-1} W$, and so $A_{V}$ does depend on $Q$. Therefore, $A_{V}$ is not an eigenvector of $\frac{C_{V} U^{-1} C_{V} W W^{\prime}}{W^{\prime} C_{V} U^{-1} C_{V} W}$ with the associated eigenvalue 1 . Hence, $\alpha_{V} \neq 0$.

Q.E.D. 
The non-zero alphas show that in contrast with the CAPM, in our model VWMP does not price assets correctly in the cross section. These alphas derive from both information asymmetry and ambiguity aversion. First, the traditional CAPM is based on homogeneous beliefs which are fully impounded in the market capitalization weights in VWMP. Hence, conditional on the asset prices, VWMP is mean-variance efficient. In contrast, in our setting, owing to information asymmetry, the average precision of private signals $(\boldsymbol{\Sigma})$ and the precision of random supply $(\boldsymbol{U})$ will determine the price signal distribution. This is directly implied by the equilibrium pricing function (equation (23)). Therefore, the weights in a portfolio that can price assets correctly must be functions of these two precisions. VWMP, however, has value weights, which are not functions of these two precisions, so it cannot be efficient conditional on asset prices in the financial market with information asymmetry. Hence, using VWMP as the pricing portfolio, the assets should have non-zero alphas.

Second, ambiguity aversion also affects appropriate index portfolio weights for asset pricing, which further contributes to nonzero alphas relative to VWMP. Intuitively, when more investors are ambiguous about an asset, its demand curve shifts leftward, leading to a lower price and a higher risk premium. We then refer to the increment in the asset's risk premium due to ambiguity aversion as the asset's ambiguity premium.

\section{The Information Separation Theorem}

In this appendix, we prove a new separation theorem in an economy with asymmetric information but without model uncertainty. ${ }^{21}$ Then the model is a traditional rational expectations equilibrium model with multiple risky assets, analyzed by Admati (1985). Proposition 8 characterizes a linear rational expectations equilibrium and shows investors' optimal risky assets holding when all parameters are common knowledge.

Proposition 8. In the model whose parameters are all common knowledge among investors, there exists an equilibrium with the pricing function

$$
P=B^{-1}[F-A-C Z],
$$

\footnotetext{
${ }^{21}$ The theorem we are about to state does not require the assumption of an uninformative prior. Since both the equilibrium pricing function and investors' equilibrium holdings are continuous in the prior precisions of assets' payoffs, substituting zero prior precision will lead to the separation theorem in the setting with a common uniform uninformed prior.
} 
where

$$
\begin{aligned}
A & =\frac{1}{\rho}\left[\rho^{2}(\Sigma U \Sigma)+\Sigma\right]^{-1} W \\
B & =r \boldsymbol{I} \\
\boldsymbol{C} & =\frac{1}{\rho} \Sigma^{-1} .
\end{aligned}
$$

Any investor i's risky asset holding is

$$
D_{i}=\left[\boldsymbol{I}+\frac{1}{\rho^{2}}(\boldsymbol{\Sigma} \boldsymbol{U})^{-1}\right]^{-1} W+\rho \boldsymbol{\Omega}_{i}\left(S_{i}-r P\right) .
$$

Proof of Proposition 8:

Let's first prove a more general version of Proposition 8, when investors hold a common prior belief about $F, F \sim \mathcal{N}(\bar{F}, V)$. As is standard in the literature of rational expectations equilibrium, we consider the linear pricing function

$$
F=A+B P+C Z, \quad \text { with } C \text { nonsingular. }
$$

If and only if $B$ is nonsingular, equation (41) can be rearranged to

$$
P=-B^{-1} A+B^{-1} F-B^{-1} C Z,
$$

which solves for prices. Recall that $S_{i}=F+\epsilon_{i}$, so conditional on $F, P$ and $S_{i}$ are independent. Therefore, we can write down assets' payoffs' posterior means and posterior variances conditional on all information that are available to investor $i$ as follows.

First consider investor $i$ 's belief about $F$ conditional on $P$. Conditional on $P, F$ is normally distributed with mean $A+B P$ and precision $\left[C U^{-1} C^{\prime}\right]^{-1}$. On the other hand, conditional on $S_{i}$, investor $i$ 's belief about $F$ is also normally distributed, with mean $S_{i}$ and precision $\Omega_{i}$. Therefore, investor $i$ 's belief about $F$ conditional on what the investor observes, $P$ and $S_{i}$, is also normally distributed. The mean of the conditional distribution of $F$ is the weighted average of the expectation conditional on the price $P$, the expectation conditional on investor $i$ 's private signal $S_{i}$, and the prior mean $\bar{F}$. Therefore, the conditional mean of $F$ is

$$
\left[\left(C U^{-1} C^{\prime}\right)^{-1}+\Omega_{i}+V^{-1}\right]^{-1}\left[\left(C U^{-1} C^{\prime}\right)^{-1}(A+B P)+\Omega_{i} S_{i}+V^{-1} \bar{F}\right] .
$$


The precision of the conditional distribution of $F$ is

$$
\left(C U^{-1} C^{\prime}\right)^{-1}+\Omega_{i}+V^{-1} .
$$

Then, from any investor $i$ 's first order condition, investor $i$ 's demand is

$$
\begin{aligned}
D_{i}= & \rho\left[\left(\boldsymbol{C} \boldsymbol{U}^{-1} \boldsymbol{C}^{\prime}\right)^{-1}+\boldsymbol{\Omega}_{i}+\boldsymbol{V}^{-1}\right] \\
& \left\{\left[\left(\boldsymbol{C} \boldsymbol{U}^{-1} \boldsymbol{C}^{\prime}\right)^{-1}+\boldsymbol{\Omega}_{i}+\boldsymbol{V}^{-1}\right]^{-1}\left[\left(\boldsymbol{C} \boldsymbol{U}^{-1} \boldsymbol{C}^{\prime}\right)^{-1}(A+\boldsymbol{B} P)+\boldsymbol{\Omega}_{i} S_{i}+\boldsymbol{V}^{-1} \bar{F}\right]-r P\right\} \\
= & \rho\left\{\left[\left(\boldsymbol{C} \boldsymbol{U}^{-1} \boldsymbol{C}^{\prime}\right)^{-1}(A+\boldsymbol{B} P)+\boldsymbol{\Omega}_{i} S_{i}+\boldsymbol{V}^{-1} \bar{F}\right]-\left[\left(\boldsymbol{C} \boldsymbol{U}^{-1} \boldsymbol{C}^{\prime}\right)^{-1}+\boldsymbol{\Omega}_{i}+\boldsymbol{V}^{-1}\right] r P\right\} \\
= & \rho\left\{\left(\boldsymbol{C} \boldsymbol{U}^{-1} \boldsymbol{C}^{\prime}\right)^{-1}(\boldsymbol{B}-r \boldsymbol{I})-r \boldsymbol{\Omega}_{i}-r \boldsymbol{V}^{-1}\right\} P \\
& +\rho \boldsymbol{\Omega}_{i} S_{i}+\rho\left[\left(\boldsymbol{C} \boldsymbol{U}^{-1} \boldsymbol{C}^{\prime}\right)^{-1} A+\boldsymbol{V}^{-1} \overline{\mathrm{F}}\right] .
\end{aligned}
$$

Integrating across all investors' demands gives the aggregated demand as

$$
\begin{array}{r}
\int_{0}^{1} D_{i} \mathrm{~d} i=\rho\left\{\left(\boldsymbol{C} \boldsymbol{U}^{-1} \boldsymbol{C}^{\prime}\right)^{-1}(\boldsymbol{B}-r \boldsymbol{I})-r\left(\int_{0}^{1} \boldsymbol{\Omega}_{i} \mathrm{~d} i\right)-r \boldsymbol{V}^{-1}\right\} P \\
+\rho\left(\int_{0}^{1} \boldsymbol{\Omega}_{i} S_{i} \mathrm{~d} i\right)+\rho\left[\left(\boldsymbol{C} \boldsymbol{U}^{-1} \boldsymbol{C}^{\prime}\right)^{-1} A+\boldsymbol{V}^{-1} \bar{F}\right] .
\end{array}
$$

By equation (1), we have $\int_{0}^{1} \boldsymbol{\Omega}_{i} \mathrm{~d} i=\boldsymbol{\Sigma}$. Also, note that

$$
\int_{0}^{1} \Omega_{i} S_{i} \mathrm{~d} i=\Sigma F .
$$

Therefore, from the market clearing condition, we have

$$
\int_{0}^{1} D_{i} \mathrm{~d} i=Z+W .
$$

In an equilibrium, both equation (41) and equation (47) hold simultaneously for any realized $F$ and $Z$, therefore, by matching coefficients in these two equations, we have

$$
\begin{aligned}
\rho\left[\left(\boldsymbol{C} \boldsymbol{U}^{-1} \boldsymbol{C}^{\prime}\right)^{-1} A+\boldsymbol{V}^{-1} \bar{F}\right]-W & =-\boldsymbol{C}^{-1} A \\
\rho\left[\left(\boldsymbol{C} \boldsymbol{U}^{-1} \boldsymbol{C}^{\prime}\right)^{-1}(\boldsymbol{B}-r \boldsymbol{I})-r \boldsymbol{\Sigma}-r \boldsymbol{V}^{-1}\right] & =-\boldsymbol{C}^{-1} \boldsymbol{B} \\
\rho \boldsymbol{\Sigma} & =\boldsymbol{C}^{-1}
\end{aligned}
$$

Therefore, from equation (50), we have

$$
C=\frac{1}{\rho} \Sigma^{-1}
$$


Obviously, $C$ is positive definite and symmetric. Then from equation (48), we have

$$
\left[\rho^{2}(\Sigma U \Sigma)+\Sigma\right] A=\frac{1}{\rho} W-V^{-1} \bar{F} .
$$

Because both $(\Sigma U \Sigma)$ and $\Sigma$ are both positive definite, we have

$$
A=\left[\rho^{2}(\Sigma U \Sigma)+\Sigma\right]^{-1}\left(\frac{1}{\rho} W-V^{-1} \bar{F}\right) .
$$

From equation (49), we have

$$
\left[\rho^{2}(\boldsymbol{\Sigma} \boldsymbol{U} \boldsymbol{\Sigma})+\boldsymbol{\Sigma}\right](\boldsymbol{B}-r \boldsymbol{I})=r \boldsymbol{V}^{-1} .
$$

Again, because $\left[\rho^{2}(\boldsymbol{\Sigma} U \boldsymbol{\Sigma})+\boldsymbol{\Sigma}\right]$ is positive definite, we have

$$
\boldsymbol{B}=r \boldsymbol{I}+r\left[\rho^{2}(\boldsymbol{\Sigma} \boldsymbol{U} \boldsymbol{\Sigma})+\boldsymbol{\Sigma}\right]^{-1} \boldsymbol{V}^{-1} .
$$

Obviously, $\boldsymbol{B}$ is invertible. By substituting $A, \boldsymbol{B}$, and $\boldsymbol{C}$ into equation (42), we solve the equilibrium pricing function.

Now, let's look at any investor $i$ 's holding. Substituting the coefficients into investor $i$ 's holding function (45), we have

$$
D_{i}=\left(\boldsymbol{I}+\frac{1}{\rho^{2}}(\boldsymbol{\Sigma} \boldsymbol{U})^{-1}\right)^{-1} W+\rho\left[\boldsymbol{I}+\rho^{2} \boldsymbol{\Sigma} \boldsymbol{U}\right]^{-1} \boldsymbol{V}^{-1}(\bar{F}-r P)+\rho \boldsymbol{\Omega}_{i}\left(S_{i}-r P\right) .
$$

Finally, because the pricing function $P$ and any investor $i$ 's demand function $D_{i}$ are continuous in $\boldsymbol{V}^{-1}$, we can substitute $\boldsymbol{V}^{-1}=0$ to get Proposition 8 .

Q.E.D.

Owing to supply shocks, asset prices are not fully revealing, so information asymmetry persists in equilibrium and different investors have different asset holdings. An investor's asset holding is the sum of two components. The first term in equation (40),

$$
\left[\boldsymbol{I}+\frac{1}{\rho^{2}}(\boldsymbol{\Sigma} \boldsymbol{U})^{-1}\right]^{-1} W
$$

is just $R A M P$, which is deterministic.

The second component of any investor's risky asset holding, the second term in (40), is what we call information-based portfolio. This position, $\rho \boldsymbol{\Omega}_{i}\left(S_{i}-r P\right)$, consists of extra holdings in the securities about which the investor has information. Investor $i$ 
holds such an extra position of an asset $n$ if and only if the $n^{\text {th }}$ diagonal entry of $\boldsymbol{\Omega}_{i}$ is $\kappa_{n}>0$. This suggests that any investor $i$ holds direct positions of a risky asset because possessing an informative signal about such an asset reduces its conditional volatility (independent of the signal realization). Investor $i$ 's direct positions of a risky asset also come from her speculation, which is taken to exploit superior information. Different investors, even if they are informed about asset $n$, hold different speculative portfolios, because they receive heterogeneous private signals.

Crucially, in each investor's equilibrium asset holdings in equation (40), the two components depend upon investors' information sets in different ways. The first component, RAMP, is formed based only on the information that the investor gleans from asset prices; it is independent of the investor's private information. In contrast, the second component, the information-based portfolio, can be formed based only on the investor's own private information; it is independent of the information content of the market price. Since the supply shock precisions do not affect the distributions of the private signals, it follows that the information-based portfolio is independent of the supply shock precisions. The reason for this independence is that each individual investor is "small" and thus her trading cannot affect the asset prices and thus the price informativeness. ${ }^{22}$ This independence implies the Information Separation Theorem, which is stated in Section 3.1 and repeated below.

Theorem (The Information Separation Theorem). When the characteristics of all assets are common knowledge, equilibrium portfolios have three components: a deterministic risk-adjusted market portfolio (RAMP); an information-based portfolio based upon private information and equilibrium prices but no extraction of information from prices; and the riskfree asset.

Theorem 1 indicates that any investor can form an optimal portfolio in separate steps: (1) buy one share of RAMP; (2) buy the information-based portfolio using only private information, not the information extracted from price; and (3) put any left-over funds into the riskfree asset. This separation theorem derives from market equilibrium as well as optimization considerations. This differs from those (non-informational) separation theorems in the literature that are based solely on individual optimization arguments. ${ }^{23}$

\footnotetext{
${ }^{22}$ Vives (2008) derives investors' equilibrium asset holdings in a single-asset environment with a normal prior and zero aggregate endowment. Therefore, his result cannot be directly used in our analysis when investors are ambiguity averse about some assets.

${ }^{23}$ It may seem puzzling that none of the three portfolio components depend on the information that an investor extracts from price. How then does this information enter into the investor's portfolio decision?
} 
In our model, the fund can provide RAMP because it knows all the model parameters, and RAMP does not include any investor's private information. Meanwhile, the information-based portfolio is exactly the same as the direct holdings of the risky assets in Proposition 1. To form the information-based portfolio, an investor does not need to extract information from the equilibrium price: she can treat the equilibrium prices as given parameters, and solve for the information-based portfolio from her CARA utility maximization problem as in a partial equilibrium model.

The answer is that RAMP is optimal precisely because of the ability of investors to extract information from price. As mentioned before, RAMP is deterministic; it does not depend on the private signals. But the fact that RAMP is an optimal choice is true only because investors update their beliefs based on price. So the optimal portfolio choice is indeed influenced by such information extraction. 


\section{References}

Admati, A. (1985, May). A noisy rational expectations equilibrium for multi-asset securities markets. Econometrica 53(3), 629-658.

Anantanasuwong, K., R. Kouwenberg, O. Mitchell, and K. Peijnenberg (2019, February). Ambiguity attitudes about investments: Evidence from the field. NBER Working paper.

Baruch, S. and X. Zhang (2018). Is Index Trading Benigh? Working paper, University of Utah.

Berk, J. B. (2005). Five myths of active portfolio management. Journal of Portfolio Management 31(3), 27-31.

Biais, B., P. Bossaerts, and C. Spatt (2010). Equilibrium asset pricing and portfolio choice under asymmetric information. Review of Financial Studies 23, 1503-1543.

Bianchi, M. and J.-M. Tallon (2018). Ambiguity preferences and portfolio choices: Evidence from the field. Management Science. forthcoming.

Bond, P. and D. García (2018). The Equilibrium Consequences of Indexing. Working paper, University of Washington, Seattle.

Bossaerts, P., P. Ghirardato, S. Guarnaschelli, and W. R. Zame (2010, April). Ambiguity in asset markets: Theory and experiment. Review of Financial Studies 23(4), 13251359.

Cao, H. H., B. Han, D. Hirshleifer, and H. H. Zhang (2011, January). Fear of the unknown: Familiarity and economic decisions. Review of Finance 15(1), 173-206.

Cao, H. H., T. Wang, and H. H. Zhang (2005, Winter). Model uncertainty, limited market participation, and asset prices. Review of Financial Studies 18(4), 1219-1251.

Chabakauri, G. and O. Rytchkov (2016). Asset Pricing with Index Investing. Working paper, London School of Economic.

Condie, S. and J. Ganguli (2011, July). Ambiguity and rational expectations equilibria. Review of Economic Studies 78(3), 821-845.

Condie, S. and J. Ganguli (2017, November). The pricing effects of ambiguous private information. Journal of Economic Theory 172, 512-557.

Dimmock, S. G., R. Kouwenberg, O. Michell, and K. Peijnenburg (2016). Ambiguity aversion and household portfolio choice puzzles: Empirical evidence. Journal of Financial Economics 119, 559-577.

Dimmock, S. G., R. Kouwenberg, and P. Wakker (2016). Ambiguity attitudes in a large representative sample. Management Science 65, 1363-1380.

Dow, J. and S. R. Werlang (1992, January). Uncertainty aversion, risk aversion, and the optimal choice of portfolio. Econometrica 60(1), 197-204.

Easley, D. and M. O'Hara (2004, August). Information and the cost of capital. Journal of Finance 59(4), 1553-1583. 
Easley, D. and M. O'Hara (2009, May). Ambiguity and nonparticipation: The role of regulation. Review of Financial Studies 22(5), 1817-1843.

Easley, D. and M. O'Hara (2010, October). Microstructure and ambiguity. Journal of Finance LXV(5), 1817-1846.

Epstein, L. G. and M. Schneider (2008). Ambiguity, information quality, and asset pricing. Journal of Finance 63(1), 197-228.

Epstein, L. G. and M. Schneider (2010). Ambiguity and asset markets. Annual Review of Financial Economics 2, 315-346.

Fama, E. F. and K. R. French (1993). Common risk factors in the returns on stocks and bonds. Journal of Financial Economics 33, 3-56.

Gennaioli, N., A. Shleifer, and R. W. Vishny (2015, January). Money doctors. Journal of Finance 70(1), 91-114.

Gilboa, I. and D. Schmeidler (1989). Maxmin expected utility with nonunique prior. Journal of Mathematical Economics 18(2), 141-153.

Grossman, S. J. and J. E. Stiglitz (1980, June). On the impossibility of informationally efficient markets. American Economic Review 70(3), 393-408.

Hellwig, M. F. (1980). On the aggregation of information in competitive markets. Journal of Economic Theory 22, 477-498.

Huang, C., F. Li, and X. Weng (2020). Star ratings and the incentives of mutual funds. Journal of Finance 75(3), 1715-1765.

Illeditsch, P., S. Condie, and J. Ganguli (2019). Information inertia. Journal of Finance. forthcoming.

Klibanoff, P., M. Marinacci, and S. Mukerji (2005, November). A smooth model of decision making under ambiguity. Econometrica 73(6), 1849-1892.

Li, Y. and C. Wang (2018). Delegation uncertainties. Working paper, Ohio State University.

Lintner, J. (1965, February). The valuation of risky assets and the selection of risky investments in stock portfolios and capital budgets. Review of Economics and Statistics 47, 13-37.

Mele, A. and F. Sangiorgi (2015). Uncertainty, information acquisition and price swings in asset markets. Review of Economic Studies 82, 1533-1567.

Sharpe, W. F. (1964). Capital asset prices: A theory of market equilibrium under conditions of risk. Journal of Finance 19, 425-442.

Van Nieuwerburgh, S. and L. Veldkamp (2009, June). Information immobility and the home bias puzzle. Journal of Finance 63(4), 1187-1215.

Van Nieuwerburgh, S. and L. Veldkamp (2010, April). Information acquisition and under-diversification. Review of Economic Studies 77(2), 779-805.

Vives, X. (2008). Information and Learning in Markets. Princeton University Press. 
Watanabe, M. (2016, November). Supply ambiguity and market fragility. Working paper, University of Alberta. 


\section{Online Appendix (not for Publication)}

\section{D.1 Single-factor Model with RAMP as Common Factor}

One interesting asset pricing implication of our model is that asset risk premia satisfy the CAPM with RAMP as the pricing portfolio. This implication holds even if investors possess asymmetric information and are subject to ambiguity aversion, as formally stated in Corollary 1. Such an asset pricing implication suggests that RAMP performs better than VWMP in a single-factor pricing model. In this appendix, we present supporting empirical evidence. ${ }^{1}$

As discussed in Section 3, RAMP includes less positions of more volatile stocks and so can be viewed as a low-volatility portfolio. Therefore, it is natural to use the lowvolatility ETF that is traded in the market as a proxy for RAMP. One candidate is the Invesco S\&P $500^{\circledR}$ Low Volatility ETF (ticker: SPLV), which tracks the S\&P $500^{\circledR}$ Low Volatility Index. The index measures performance of the 100 least volatile stocks in the S\&P 500, with the least volatile stocks receiving the highest weights. Since the index was launched in 2011, the sample period is from June 2011 to December 2020.

Table 1 shows the estimations of a single-factor model with VWMP and the Invesco S\&P $500^{\circledR}$ Low Volatility ETF as common factors.

\begin{tabular}{ccc}
\hline & VWMP & SPLV \\
\hline$|\alpha|$ & 0.409 & 0.252 \\
$t$ & 1.66 & 0.65 \\
$R^{2}$ & 0.81 & 0.46 \\
\hline
\end{tabular}

Table 1: A Single-factor Model with VWMP and SPLV as common factors from June 2011 to December 2020 (estimated $\alpha$ in percentage)

Table 1 demonstrates that as a proxy of RAMP, the low volatility ETF performs better than $V W M P$ in asset pricing. With VWMP being the pricing portfolio, the average absolute value of alphas is $0.409 \%$ and is statistically significant (with the $t$-statistic being 1.66). When we replace VWMP with the low volatility ETF, the average absolute value of alphas decreases to $0.252 \%$ and becomes insignificant (with the $t$-statistic being 0.65 ).

One issue of the test in Table 1 is that the $R^{2}$ is low when we use the low volatility ETF as the pricing portfolio. This may be due to the short sample period and the fact

\footnotetext{
${ }^{1}$ To perform the empirical tests, we follow Fama and French (1993) to construct testing portfolios. Specifically, we use the $5 \times 5$ portfolios based on size and book-to-market ratio as the test portfolios.
} 
that the index that the low volatility ETF tracks includes 100 stocks only. We therefore construct a volatility-weighted market portfolio as a proxy of RAMP so that we can run the tests over a longer period. Specifically, we construct a portfolio MKTSD as

$$
\operatorname{MKTSD}_{t}=\frac{\sigma_{i, t}^{-1}}{\sum \sigma_{i, t}^{-1}} \operatorname{Ret}_{i, t},
$$

where $\operatorname{Ret}_{i, t}$ is the monthly return of stock $i$ in month $t$, and $\sigma_{i, t}$ is the standard deviation estimated using the three-year rolling window of monthly returns.

We then test the single-factor model using VWMP and MKTSD as common factors over the sample period from December 1963 to December 2020. The estimations reported in Table 2 show that MKTSD outperforms VWMP in all three metrics (i.e., $|\alpha|, t$, and $R^{2}$ ).

\begin{tabular}{ccc}
\hline & VWMP & MKTSD \\
\hline$|\alpha|$ & 0.199 & 0.153 \\
$t$ & 1.72 & 1.45 \\
$R^{2}$ & 0.748 & 0.784 \\
\hline
\end{tabular}

Table 2: A Single-factor Model with VWMP and MKTSD as common factors from December 1963 to December 2020 (estimated $\alpha$ in percentage) 